Portland State University

PDXScholar

9-15-2021

\title{
Forest Fire Effects on the Temporal Variability of Landscape Snow Albedo Relative to Burn Severity
}

Max Gersh

Portland State University

Follow this and additional works at: https://pdxscholar.library.pdx.edu/open_access_etds

Part of the Environmental Sciences Commons, and the Remote Sensing Commons Let us know how access to this document benefits you.

Recommended Citation

Gersh, Max, "Forest Fire Effects on the Temporal Variability of Landscape Snow Albedo Relative to Burn Severity" (2021). Dissertations and Theses. Paper 5800.

https://doi.org/10.15760/etd.7671

This Thesis is brought to you for free and open access. It has been accepted for inclusion in Dissertations and Theses by an authorized administrator of PDXScholar. Please contact us if we can make this document more accessible: pdxscholar@pdx.edu. 
Forest Fire Effects on the Temporal Variability of Landscape Snow Albedo Relative to Burn Severity

\title{
by
}

Max Gersh

A thesis submitted in partial fulfillment of the requirements for the degree of

\author{
Master of Science \\ in \\ Environmental Science and Management
}

Thesis Committee:

Kelly Gleason, Chair

Max Nielsen-Pincus

Geoffrey Duh

\author{
Portland State University \\ 2021
}


(C) 2021 Max Gersh 


\begin{abstract}
Snow-water storage is decreasing, while forest fires are increasing in duration, size, frequency, and intensity, due to climate change. Most forest fires occur in the seasonal snow zone, altering snow mass and energy balance for many years following fire. Following forest fires, Surface snow albedo (SSA) decreases, as light absorbing particles (LAP), particularly black carbon (BC) produced in forest fires get deposited throughout the snowpack, altering snowpack energy balance driving earlier snowmelt in burned forests. While SSA decreases, landscape snow albedo (LSA) increases following fire, as more of the snow-covered surface becomes visible beneath the burned forest canopy, brightening the snow albedo of the broad-scale landscape surface. Altered snow albedo has major hydrologic and climatic implications, impacting the environment and human life. We used MOD10A1 from the Moderate Resolution Imaging Spectroradiometer (MODIS) instrument to acquire daily snow albedo data from January $1^{\text {st }}-$ April $30^{\text {th }}, 2000-2019$. The daily snow albedo was evaluated before and after fire occurrences, across a chrono-sequence of eight burned forests, relative to burn severity, years since fire occurrence, and forest density. LSA displayed a persistent increase for at least ten years following a fire, with a total increase of $33 \%$ across all eight forest fires and burn severity classifications over the entire temporal analysis. Two-thirds of that increase came the year immediately following the fire. High burn severity LSA observed a total increase of $63 \%$, the highest difference for all burn severity classifications for the study. Moderate burn severity and unburned forest LSA saw an increase of 53\% and $51 \%$, respectively. When we examined seasonal LSA following a fire, winter experienced
\end{abstract}


higher-than-average values whereas spring experienced lower-than-average values. For the post-fire analysis, a generalized additive model (GAM), multivariate linear regression models, and linear spline regression models of normalized LSA indicated that following the initial increase in LSA due to a forest fire disturbance, LSA remains relatively constant, increasing only slightly each year, until approximately six years post-fire, where a change in the rate of increase becomes greater, resulting in a delayed brightening effect in LSA. Therefore, resulting in a large portion of post-fire snow albedo change (PFSAC) to occur between the period of six to ten years post fire. The results indicated that the rate of increase in LSA slowed after approximately ten years following a fire, suggesting LSA in previously burned forests progress to become like that of an unburned, open meadow. 


\section{Acknowledgements}

First of all, I would like to thank Portland State University and the NASA Terrestrial Hydrology Program. None of this would have been possible without the opportunity I have been provided with, or the funding behind the study. This research was supported by NASA’s Terrestrial Hydrology Program Award \#80NSSC19K0002.

I am grateful for the support and guidance from my advisor, Dr. Kelly Gleason; this study would not have been possible without her expertise and leadership. I would not be where I am without her dedication to science and enthusiasm to educate. I am very appreciative for the support from Dr. Max Nielsen-Pincus and Dr. Geoffrey Duh, the other members of my committee. I am grateful for their willingness to provide beneficial knowledge and feedback on many subjects.

Additionally, I am grateful for the support and encouragement from my peers at Portland State University, especially my fellow labmates in Dr. Kelly Gleason's Snow Lab, Anton Surunis and Megan Guinn. Finally, I am forever grateful for the limitless support and patience from my partner, Caitlin Wrycza, and the endless support and encouragement from my parents, Cynthia Driskell and Cory Gersh. 
Table of Contents

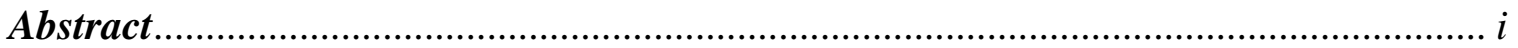

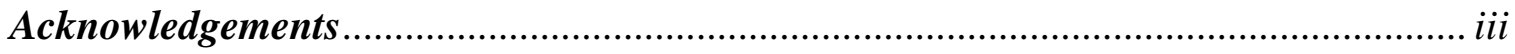

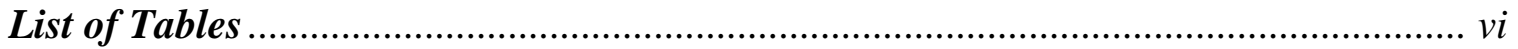

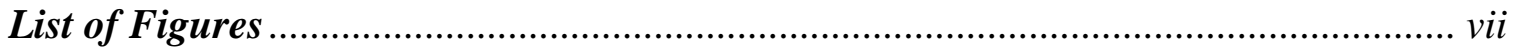

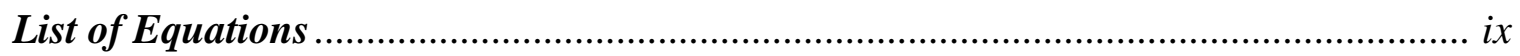

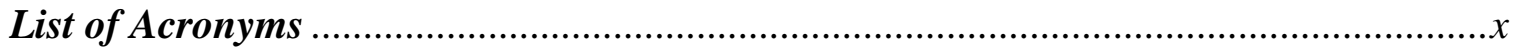

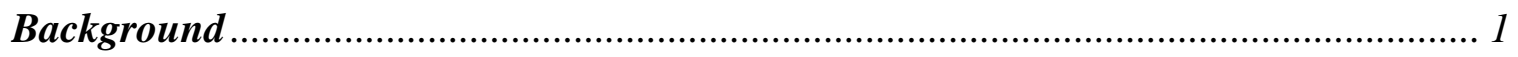

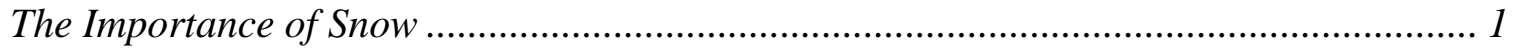

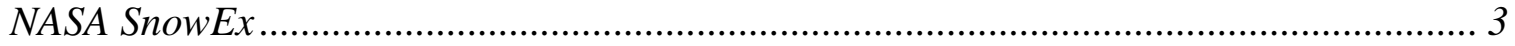

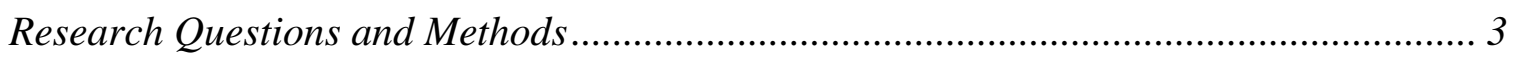

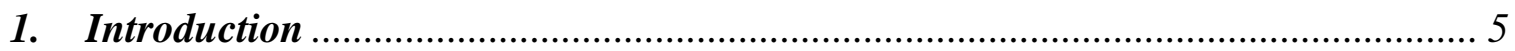

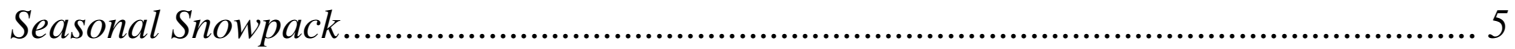

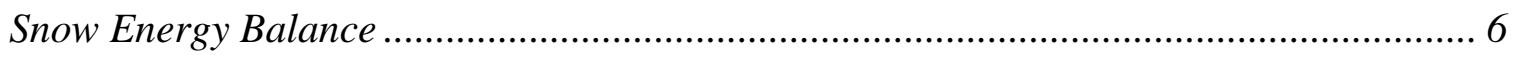

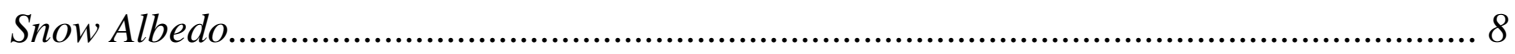

Hydrologic and Climatic Implications................................................................... 12

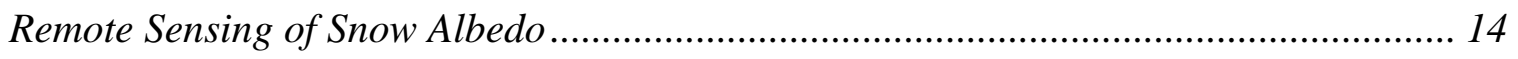

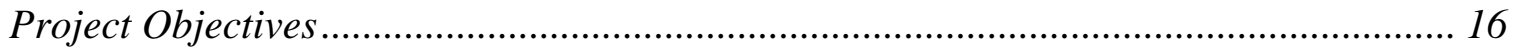

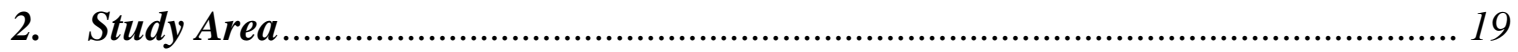

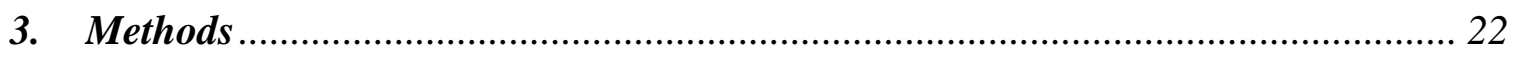

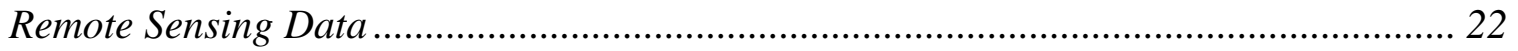

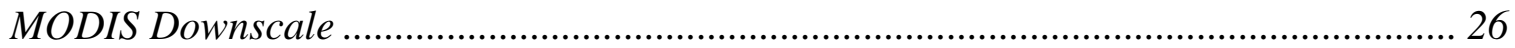

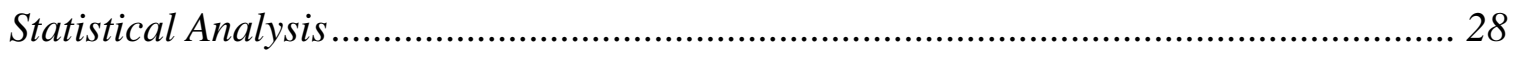

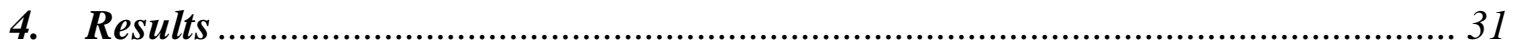

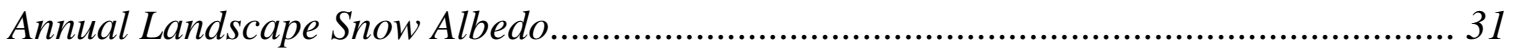

Annual Post-fire Snow Albedo Change ..................................................................... 36

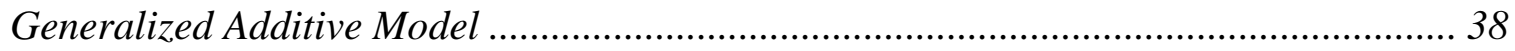

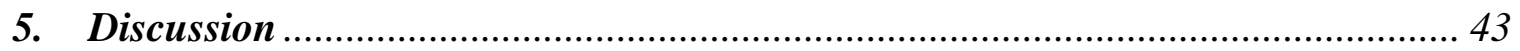

Quantifying Post-fire Landscape Snow Albedo ....................................................... 43

Post-fire Snow Albedo Temporal Variation................................................................ 45 
Post-fire Snow Albedo Spatial Variation................................................................... 47

Landscape and Climate Effects on Snow Albedo........................................................ 49

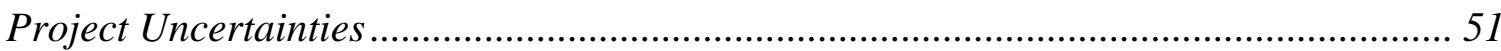

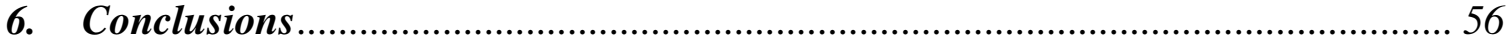

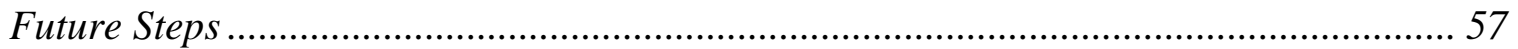

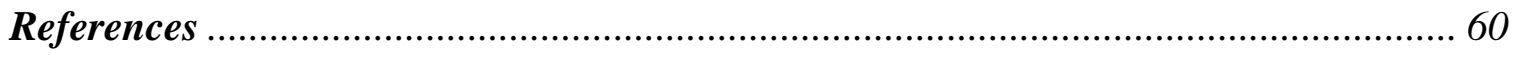

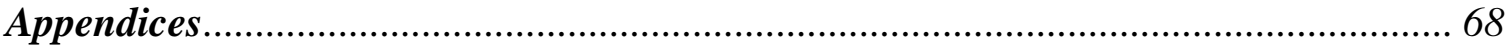

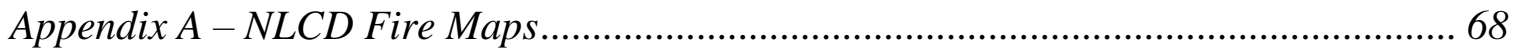

Appendix B - Normalized Pre-fire vs. Post-fire LSA..................................................... 69

Appendix C-Post-fire Landscape Snow Albedo ............................................................ 71

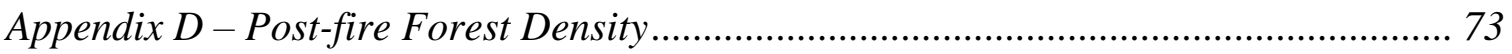

Appendix E - Post-fire Snow Albedo Change............................................................. 75 
List of Tables

Table 1. Names and characteristics of the eight fire sites involved in the study of forest fire effects on snow albedo.

Table 2. Relevant remote sensing products used during this study. 23

Table 3. Pre-fire and post-fire LSA statistics for all eight fires separately including the mean difference and percent increase for each fire. $* * *=p<0.001$ 34

Table 4. Results from the daily normalized LSA Tukey HSD test based on the piecewise comparisons of burn severity classification in post-fire comparisons and pre- vs. post-fire

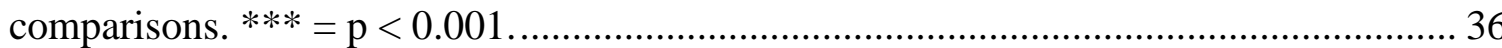

Table 5. Percentage PFSAC increase relative to each burn severity. ............................ 37

Table 6. Results of the multivariate linear regression model for the rate of PFSAC as a function of years post fire and forest density, relative to each burn severity. $* * *=p<$ 0.001

Table 7. Results of the linear spline regression models for normalized LSA as a function

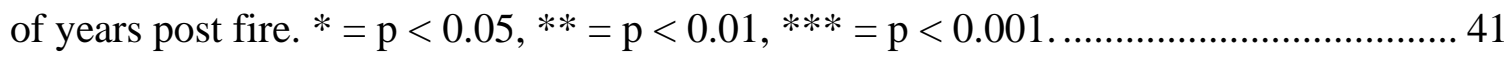




\section{List of Figures}

Figure 1. Hypothesized results of FFESA for each burn severity classification including pre-fire conditions, initial post-fire increase in LSA, and post-fire snow albedo recovery. The focus of the study is on the immediate and persistent FFESA. 18

Figure 2. Fire site locations within the study area in western Wyoming with watershed boundary lines throughout the area. Top left: Western US with the study area focused on in the black box with the Columbia, Colorado, and Missouri River Basins labeled....... 20

Figure 3. Example of the downscaling process complete for every daily snow albedo measurement and annual forest density measurement. The MODIS data was resampled, then cropped to fit the fire area, then evaluated for each burn severity classification...... 27

Figure 4. Pre-fire and post-fire LSA separated by high burn (black), moderate burn (gray), unburned forest (green), open area (blue), buffer forest (light green), and buffer open (light blue). The larger squares represent the pre-fire and post-fire averages.

Figure 5. Winter \& Spring pre-fire and post-fire LSA separated by high burn (black), moderate burn (gray), unburned forest (green), and open area (blue). The large squares and circles represent the pre-fire and post-fire Winter and Spring mean LSA, respectively.

Figure 6. a) Post-fire annual LSA. b) Post-fire annual Winter LSA. c) Post-fire annual Spring LSA. Each boxplot represents the whole fire area. The linear regression line for each plot is presented in the bottom right of the plot.

Figure 7. Normalized LSA results for post-fire snow albedo change. High burn (black), moderate burn (gray), and unburned forest (green) were normalized by taking the differenced LSA of the buffer forest area. Open area (blue) was normalized by taking the differenced LSA of the buffer open area. 38

Figure 8. GAM representation of smooth functions (years post fire and forest density) as predictor variables with normalized LSA as the response variable.

Figure 9. Linear spline regression representation with two knots (three segments) to show the multiple levels of PFSAC relative to high burn (black), moderate burn (gray), unburned forest (green), open area (blue) and combined for whole fire area (red)......... 42 
Figure 10. NLCD site maps for each individual fire. Areas within each burn perimeter

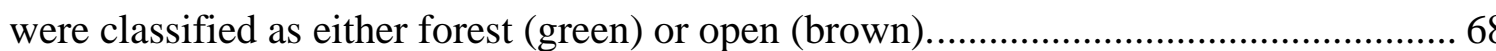

Figure 11. Pre-fire and post-fire normalized LSA for each fire, relative to burn severity. a) Boulder Fire b) Bull Fire c) Cliff Creek Fire d) Green Knoll Fire e) Horsethief Canyon Fire f) Lava Mountain Fire g) Purdy Fire h) Roosevelt Fire

Figure 12. Post-fire landscape snow albedo separated by each fire. a) Boulder Fire b) Bull Fire c) Cliff Creek Fire d) Green Knoll Fire e) Horsethief Canyon Fire f) Lava Mountain Fire g) Purdy Fire h) Roosevelt Fire

Figure 13. Post-fire forest density measurements separated by fire. a) Boulder Fire b) Bull Fire c) Cliff Creek Fire d) Green Knoll Fire e) Horsethief Canyon Fire f) Lava Mountain Fire g) Purdy Fire h) Roosevelt Fire

Figure 14. Post-fire normalized landscape snow albedo per 5-year subsets in order to observe the rate of PFSAC relative to each burn severity for each fire. a) Boulder Fire b) Bull Fire c) Cliff Creek Fire d) Green Knoll Fire e) Horsethief Canyon Fire f) Lava Mountain Fire g) Purdy Fire h) Roosevelt Fire 
List of Equations

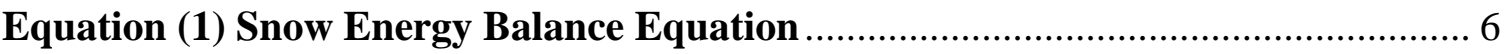

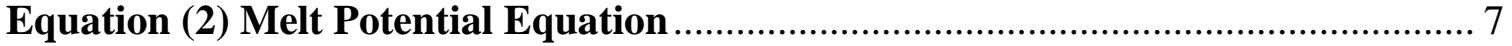

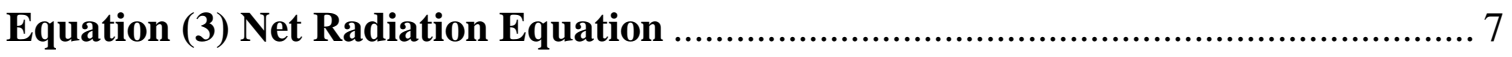

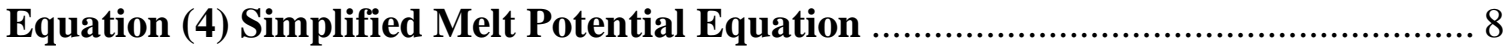

Equation (5) Multivariate Linear Regression Model ............................................. 40

Equation (6) Linear Spline Regression Models ......................................................... 41 


\section{List of Acronyms}

Fire Names:

$\mathrm{BOF}=$ Boulder Fire

$\mathrm{BUF}=$ Bull Fire

$\mathrm{CCF}=$ Cliff Creek Fire

GKF $=$ Green Knoll Fire

$\mathrm{HCF}=$ Horsethief Canyon Fire

LMF $=$ Lava Mountain Fire

PUF $=$ Purdy Fire

ROF $=$ Roosevelt Fire

\section{Burn severity classifications:}

Pos BOp $=$ Post-fire buffer open area

Pos BUnb = Post-fire buffer unburned forest

Pos $\mathrm{Hi}=$ Post-fire high burn severity

Pos Mod = Post-fire moderate burn severity

Pos Op = Post-fire open area

Pos Unb $=$ Post-fire unburned forest

Pre BOp $=$ Pre-fire buffer open area

Pre BUnb $=$ Pre-fire buffer unburned forest

Pre Hi = Pre-fire high burn severity

Pre Mod = Pre-fire moderate burn severity

Pre $\mathrm{Op}=$ Pre-fire open area

Pre Unb $=$ Pre-fire unburned forest

\section{General terms:}

$\mathrm{BC}=$ Black carbon

$\mathrm{BWD}=$ Burned woody debris

$\mathrm{dNBR}=$ Differenced normalized burn ratio

EROS $=$ Earth Resources Observation and Science

FFESA $=$ Forest fire effects on snow albedo

LAP $=$ Light absorbing particles

LSA $=$ Landscape snow albedo

MODIS = Moderate Resolution Imaging Spectroradiometer

MTBS $=$ Monitoring Trends in Burn Severity

NDSI $=$ Normalized differenced snow index

NLCD = National Land Cover Database

PFSAC $=$ Post-fire snow albedo change

RdNBR $=$ Relativized differenced normalized burn ratio

SDD $=$ Snow disappearance date

SSA $=$ Surface snow albedo

THP $=$ Terrestrial Hydrology Program

USGS = US Geological Survey

$\mathrm{VCF}=$ Vegetation continuous fields

VIIRS = Visible Infrared Imaging Radiometer Suite 


\section{Background}

The Importance of Snow

Snow is a critical component to human life, especially in the western US.

Mountain snowpack is like a frozen reservoir in that many communities get a large portion of their water from snowpack that lingers at high altitudes well into the warm months. Nearly three-quarters of the water in the western US depends on these frozen reservoirs (Viviroli et al., 2007; Mankin et al., 2015). They melt and become the water in which people drink and use for agriculture, all while feeding reservoirs and generating hydroelectricity. Snow accumulates in large quantities throughout the mountainous areas of the western US (Barnett et al., 2005). Before humans begin to see direct benefits from snowmelt runoff, the snow is aiding in essential processes that cool the planet (Berghuijs et al., 2014; Mankin et al., 2015). The extent and albedo of the snow is crucial in these cooling processes (Flanner et al., 2011; Derksen and Brown, 2012). Most natural surfaces, like soil and forests, absorb approximately $80 \%$ or more of incoming solar energy, which has a warming effect. Fresh snow is known to have some of the highest albedo of any natural substance on Earth, reflecting up to $95 \%$ of solar energy in the visible wavelength range, which has a significant cooling effect (Jin et al., 2008; Singh et al., 2010). With more snow accumulation comes a more stable and insulating snowpack, resulting in more effective cooling for a longer duration. However, changes in seasonal snowpack, both quality and quantity, are occurring across the western US (Pierce and Cayan, 2013; Lettenmaier et al., 2015). Remote sensing provides the means of measuring these changes, although it is very difficult to measure how and why these changes are 
occurring. One connection that has been made in negatively impacting the quality and quantity of snow is forest fires. Forest fires are increasing in intensity, size, frequency, and season duration across the western US due to climate change (Westerling, 2006; Krawchuk et al., 2009; Littell et al., 2009; Jolly et al., 2015). The distribution of forest fires and their impact on Earth systems is spatially and temporally diverse (Archibald et al., 2013; Whitlock et al., 2010). While the warming climate is a clear driver, anthropogenic factors also alter the global patterns of fire frequency and pattern, as fires are undoubtedly increasing in all aspects (Krawchuk et al., 2009). In the mountainous western US, where most forest fires occur in the seasonal snow zone, we are experiencing a reduction in seasonal snowpack volume (Gleason et al., 2016) and associated snowwater storage, resulting in accelerated snowmelt and earlier springtime snow runoff release (Barnett et al., 2005; Stewart et al., 2005; Abatzoglou et al., 2011; Pederson et al., 2013; Gleason et al., 2019).

While forest fires have been directly linked to reducing seasonal snowpack through the deposition of light absorbing impurities (LAP), predominately black carbon (BC), which has a direct impact on water supply and availability (Gleason et al., 2013; Gleason et al., 2016); it is equally important to understand the impact reducing seasonal snowpack has on Earth's climate system. Earlier snowmelt, and the reduction of snowcovered area during spring, results in Earth absorbing more solar radiation, therefore accelerating climate warming. Many climate predictions take this effect into account; however, it is still one of the main uncertainties of the radiation budget in climate models (Derksen and Brown, 2012). 
NASA SnOWEX

SnowEx is a program introduced by the NASA Terrestrial Hydrology Program (THP). SnowEx was initiated in order to address some of the most critical gaps in snow remote sensing and modeling. It focuses on a combination of aerial operations and field work in order to acquire data to compare and correct for various types of snow and terrain. Scientific goals of SnowEx are to characterize the spatio-temporal variability in Earth's terrestrial snow, to quantify the snow energy and mass balances and to understand the role of snow in Earth's climate, water, and carbon cycles. In addition, an application goal of SnowEx is to improve the accuracy and precision of snow accumulation and snowmelt estimation for water supply, agriculture, energy, and hazard in order to enhance future forecasting. Our work will benefit the studies associated with SnowEx, with hopes of improving our understanding of forest fire effects on snow albedo (FFESA).

\section{Research Questions and Methods}

Evaluating FFESA is essential in expanding our understanding of fire implications on snow accumulation and melt as well as many climatic processes. With the use of remote sensing, we are able to readily acquire spatio-temporal data that may help us resolve some uncertainty regarding this issue. In this study, we evaluated daily snow albedo before and after fire occurrence across a chrono-sequence of eight burned forests, relative to burn severity, years since fire occurrence, and forest density, using the MOD10A1 remote sensing data product, obtained from the Moderate Resolution Imaging Spectroradiometer (MODIS) instrument. In analyzing the daily snow albedo measurements throughout multiple past fires, our main goal was to study the spatio- 
temporal variability associated with FFESA. Additionally, we investigated the rate of post-fire snow albedo change (PFSAC) and analyzed these measurements throughout four different burn severities. We examined the temporal shifts of landscape snow albedo (LSA) for more than a decade and quantified overall change in LSA. These findings could be used to better understand snow albedo change over time following a forest fire event in burned forested watersheds, as well as improve hydrology and climate models. 


\section{Introduction}

Seasonal Snowpack

Seasonal snowpack in the western US is a critical factor in the overall hydrological cycle, supplying and sustaining human and ecosystem needs. Hydrological models show that over half of the total runoff in the western US, and as much as $70 \%$ in mountainous areas, originates as snowmelt (Li et al., 2017). The seasonal snowpack produces more runoff than rainfall and acts as a critical water reservoir, providing much of the water used for agriculture, municipal, and industrial uses (Tague and Grant, 2009; Mote et al., 2018). In addition, snowmelt has a significant impact on recharging aquifers and nourishing the rivers, streams, and tributaries into the following summer and fall (Tague and Grant, 2009; Buytaert et al., 2011, Li et al., 2017), providing important moisture for soils and vegetation.

Temperature and precipitation variability associated with climate change have always been present, however, research points to a significant anthropogenic factor tied to current climate change activities (Houghton et al., 1996). Climate change and rising air temperatures have reduced seasonal snowpack, which lead to earlier springtime snowmelt (Stewart et al., 2005; Barnett et al., 2005; Abatzoglou et al., 2011; Pederson et al. 2013; Gleason et al., 2019), altering downstream runoff and water availability (Barnett et al., 2005; Barnhart et al., 2016; Gleason et al., 2019), ultimately leading to reduced summer soil moisture. The collective decrease in seasonal snowpack and summer soil moisture leads to an increase in potential dead fuel (Gergel et al., 2017), increasing the probability of seasonal fire risk. Anthropogenic factors and increasing fire risks are not only 
changing the extent and complexity of forest heterogeneity, but they are also accelerating the depletion of seasonal snowpack, which has implications for water use and availability for millions of people in the western US, including a potentially significant decrease in snow-water storage, intensifying the dry season water scarcity (Li et al., 2017).

Snow Energy Balance

The snow energy balance is crucial in understanding the melt potential of a snowpack. We can think of this occurring in three main phases (Dingman, 2002):

1. Warming phase: Where absorbed energy raises the average snowpack temperature to a point at which the snowpack becomes isothermal, meaning no vertical temperature gradient through the entire snowpack depth, at $0^{\circ} \mathrm{C}$.

2. Ripening phase: Once the snowpack is isothermal, the absorbed energy is then used to melt the snow. However, the meltwater is retained in the snowpack in pore spaces by surface tension forces. As the pore spaces fill completely, the snowpack is said to be "ripe" because it cannot retain any more liquid water.

3. Output phase: Further absorption of energy produces water output, which then moves out of the system as runoff, infiltration, or evaporation.

The general snow energy balance equation can be expressed as

Equation (1)

$$
\Delta S=K_{n e t}+L_{n e t}+H+L E+R+G
$$

where $\Delta \mathrm{S}$ is the change in storage, $\mathrm{K}_{\text {net }}$ is the net shortwave radiation flux, $\mathrm{L}_{\text {net }}$ is the net longwave radiation flux, $\mathrm{H}$ is the turbulent sensible heat flux, $\mathrm{LE}$ is the turbulent 
latent heat flux, $\mathrm{R}$ is heat input from rain, and $\mathrm{G}$ is the conductive exchange of sensible heat with the ground. Due to the scope of this study, we were able to consider R and G negligible.

The snow energy balance in alpine zones is dominated by net radiation during snowmelt (Marks and Dozier, 1992). Shortwave snow albedo can highly affect the rate of melt during the ablation period because it can decrease from $80-90 \%$ down to $50 \%$ or less (Wiscombe \& Warren, 1980). For a typical snowpack, the energy balance can be expressed as

Equation (2)

$$
M_{p}=K_{n e t}+L_{n e t}+H+L E
$$

where $\mathrm{M}_{\mathrm{p}}$ is the potential energy available for melt. In a majority of cases, sensible and latent heat tend to be negligible, and cancel one another out (Marks and Dozier, 1992). The equation is then left with shortwave and longwave radiation controlling snow melt. Shortwave and longwave radiation can be combined to be expressed as net radiation, $\mathrm{S}_{\text {net. }}$ Net radiation can be expressed as

Equation (3)

$$
S_{n e t}=S_{\downarrow}(1-\alpha)+l_{\downarrow}+l_{\uparrow}
$$

$\mathrm{S}_{\downarrow}$ is the incoming shortwave radiation, $\mathrm{I}_{\downarrow}$ and $\mathrm{I}_{\uparrow}$ are incoming and outgoing longwave radiation, respectively, and 1 - $\alpha$ is the co-albedo. In a typical unburned forest, the magnitude of $1_{\downarrow}$ is typically smaller than that of $1_{\uparrow}$ due to most snow existing near the melting point and causing its longwave radiation losses to be greater than that of the downward radiation from the atmosphere (Bair et al., 2020). However, in cases of an 
open area or burned forest, longwave radiation may be considered negligible for simplicity. Therefore, the melt potential in a burned forest area can be simplified to

Equation (4)

$$
M_{p}=S_{\downarrow}(1-\alpha)
$$

This simplified melt potential equation shows the importance of incoming shortwave radiation and snow albedo, $\alpha$, on snow melt (Bair et al., 2020).

Forest fires occurring in alpine zones damage and cause widespread destruction of the forest canopy. An estimated $372 \%$ to $443 \%$ increase in solar energy is absorbed by the snowpack beneath burned forests in post-fire locations (Gleason et al., 2019). In addition, increased deposition of black carbon (BC) from burned woody debris (BWD) and the charred canopy results in reduced snow albedo (Gleason et al., 2013). These changes are collectively referred to as post-fire radiative forcing on snow. By way of decreasing canopy cover, forest fires modify the snow energy balance and alter the spatio-temporal pattern of snow accumulation and ablation (Burles and Boon, 2011; Winkler, 2011). These spatio-temporal patterns of snow accumulation and ablation refer to the changing process of snowpack dynamics on a landscape scale and are crucial in understanding forest fire effects on snow albedo (FFESA). The landscape-scale measure of snow albedo is referred to as landscape snow albedo (LSA).

Snow Albedo

Snow albedo is an important factor in controlling shortwave radiation, which is a key component in snowpack energy balance. Albedo is the reflectivity or reflected proportion of the incoming shortwave solar radiation. Snow cover and its high reflectivity 
are essential for climate cooling across much of the northern hemisphere. By increasing the proportion of shortwave radiation reflected from the Earth's surface, snow covered areas produce a $1.5^{\circ} \mathrm{C}$ to $4.5^{\circ} \mathrm{C}$ cooling effect compared to snow-free surfaces (Mote, 2008; Burakowski et al., 2015). In addition, fresh snow is known to have some of the highest albedo of any natural substance on Earth, up to $0.9-0.95$, significantly increasing the cooling effect (Jin et al., 2008; Singh et al., 2010). However, fresh snow albedo can decrease to 0.2-0.4 within 2 weeks ( $O^{\prime}$ Neill and Gray, 1973). This is due to snowpack evolution processes that drive increasing snow grain size, and associated variation in snow albedo, which lead to increases in radiation absorbed by the surface (Warren and Wiscombe, 1980; Amaral et al., 2017). Snow albedo is highly reflective in the visible wavelengths, and just a small decrease can significantly increase the degree of radiation absorbed by the snowpack (Dozier et al., 2009; Gleason et al., 2013). Particles in the snow, such as $\mathrm{BC}$, brown carbon, and dust, drastically decrease snow albedo, increasing the radiative heat forcing on the snowpack, and lead to accelerated snow melt (Painter et al. 2007; Painter et al., 2012; Skiles et al., 2012; Gleason et al., 2013). Along with impurities darkening snow albedo, several other factors play into snow albedo decay including the grain-shape and grain-size of snow particles, the solar zenith angle, surface roughness and the thickness of the overall snow layer (Grenfell et al., 1994; Curry et al., 1996; Wang \& Zeng, 2010). Outside of impurities in the snow, the grain-size of snow particles has the most impact on controlling snow albedo decay (Wang \& Zeng, 2010). Over the timeframe of days-to-weeks, as snow ages, snow albedo decreases exponentially with the rate of decrease dependent on impurities, such as $\mathrm{BC}$ (Warren and Wiscombe, 1980) and BWD (Gleason et al., 2013), deposited throughout the snowpack. Impurities 
lead to an increase in snow grain-size due to the constant melting and refreezing processes that occur throughout the snowpack. These processes increase the presence of ice in the snowpack, which then cause an increase in the path length that solar radiation must travel between scattering opportunities, hence reducing snow albedo (Warren, 1982). While the presence of new snow drives the increase in snow albedo, the mechanisms that drive daily snow albedo decay and snow grain-size are much more complex and difficult to predict (Hall and $Q u, 2006$ ).

Increases in forest fire intensity, size, frequency, and season duration due to climate change (Krawchuk et al., 2009; Littell et al., 2009; Jolly et al., 2015) has also played a significant role in reducing overall seasonal snowpack volume (Gleason et al., 2016). Within the last several decades, there has been a noticeable increase in forest fires across the western US (Westerling, 2006; Krawchuk et al., 2009; Littell et al., 2009; Jolly et al., 2015), particularly during early snow melt years. Forest fires leave behind charred forests which stand blackened for decades following forest fire occurrence. Burned forests deposit BC, a light absorbing particle (LAP), along with BWD, which both act to darken snowpack and dramatically reduce snow albedo (Warren and Wiscombe, 1980). $\mathrm{BC}$ and $\mathrm{BWD}$ deposited into the snowpack throughout the winter, concentrates on the surface during snowmelt, and reduces snow albedo. LAP in the snowpack significantly accelerate snow albedo feedbacks in burned forests. Paired with the subsequent increase in shortwave radiation absorbed by the snowpack results in accelerated snowmelt and earlier snow disappearance dates (SDD; Gleason and Nolin, 2016), an effect that persists for many years following a forest fire occurrence (Gleason et al., 2019). 
While snow albedo is important in climate cooling, it is also important in largescale hydrological processes. Immediately following forest fires, surface snow albedo (SSA) dramatically darkens, but over the following ten to fifteen years may "recover" to near pre-fire concentrations of snow impurities and associated SSA (Gleason et al., 2019). Earlier snow disappearance drastically alters watershed hydrological processes, contributing to seasonal drought and the increased probability of future forest fires.

When thinking about the effects of snow albedo, it is important to distinguish between LSA and SSA. LSA has a larger effect on climate cooling and is important in dealing with climatic changes, while SSA has a larger effect on snow accumulation and ablation processes and is important in dealing with snowpack changes. LSA incorporates the effects of SSA but is also highly dependent on landcover and forest density, while SSA is more dependent on subsurface snowpack interactions and snow grain-size. Both LSA and SSA are significantly affected by forest fires, however, it is expected to see an increase in LSA and a decrease in SSA following a forest fire event.

A positive feedback loop circulates around climate change including accelerated snowmelt, increasing seasonal drought, rising air temperatures, and increasing forest fires. LSA and SSA are critical pieces to this feedback loop, both influencing the increase of snow grain-size and effecting the overall rate of snowmelt (Bair et al., 2020). This feedback process amplifies land surface-atmosphere radiative response, resulting in measurable hydrological changes (Ueyama et al., 2014; Gleason et al., 2016). Quantifying the spatio-temporal effects of FFESA will assist in understanding the hydrologic and climatic implications of this feedback loop and how the future water 
vulnerability and availability will be impacted, especially under a warming climate (Nolin and Daly, 2006; Barnett et al., 2008; Westerling et al., 2011).

\section{Hydrologic and Climatic Implications}

While the connection between forest fires and declining snowpack in the Western US is well-recognized, forest fire effects on snow accumulation, ablation, snowpack energy balance, and the resulting hydrologic and climatic implications are not as wellknown (Coop et al., 2020). Even though albedo is critical in influencing climate predictions, it is still one of the main uncertainties of the radiation budget in climate models. In pine dominated forests, seasonality of land surface albedo is large. Land surface albedo can vary between $7-80 \%$ depending on the season. Especially in the seasonal snow zone, where the snow-cover plays an important role in annual albedo averages. Forest species, density, and understory vegetation also play a large role in annual albedo averages. Additionally, the effect of canopy shadowing darkening snow surfaces has been measured to be as relevant as the effect of snow in the canopy structure (Webster and Jonas, 2018). In areas dominated by coniferous forests, positive climate forcing (warming) during the winter plays an important role in overall climate fluctuations. As large fires increase in forested areas, landcover becomes modified, leading to significant changes in snow properties. Forest fires clearly influence the climate through the release of initial aerosol and gas emissions and subsequent surface albedo feedbacks (Bowman et al., 2009; Flanner et al., 2011; McGuire et al., 2006; Randerson et al., 2006). The factors affecting vegetation regeneration after a forest fire event are very complex (Randerson et al., 2006) and the long-term effects of fire on 
radiative forcing and climate continue to be heavily studied. In many high severity fires, forested areas are not able to recover to their pre-fire conditions, remaining a heterogeneous mix of shrubland (Coppoletta et al., 2016). This alters the fire risk of the areas, in that high severity burns are more likely in the less-fire tolerant conditions. This pattern of high severity fires leading to future high severity re-burns has been seen in multiple areas across the Western US (Collins et al., 2009; Harvey et al., 2016).

Some evaluations indicate that LSA changes following a forest fire, due to increased snow exposure, may be significant enough to neutralize the initial carbon release caused by the fire, and thus may not necessarily accelerate climate warming to a significant degree (Bala et al., 2007; Randerson et al., 2006). Pre-fire landcover type is important in limiting LSA of an area based on the presence or absence of canopy cover and forest density (Burakowski et al., 2015). Forest tree canopies shield highly reflective snow surfaces, lowering overall surface albedo when snow is present, resulting in positive climate forcing relative to non-forested lands covered with snow (Bonan, 2008; Burakowski et al., 2015). By way of significantly burning tree canopies and changing ecosystem structure, forest fires drastically increase snow surface exposure in the winter and spring months, leading to an increase in LSA. The exposed snow surfaces become susceptible to direct shortwave radiation, making snow albedo even more crucial in its effect on overall climate cooling. 


\section{Remote Sensing of Snow Albedo}

Remote sensing satellite imagery analysis is essential in improving the understanding of FFESA and the potential effect these forest fires have on downstream water resource availability and overall forest heterogeneity. Past snow remote sensing efforts do not consider the forest density and forest density disturbances in post-fire areas. This is an important issue because regions with significant snow-cover coincide with widespread burned forests. As seasonal snowpack continues to decline, it may also be more vulnerable as a result of increasing forest fires. In the Western US, change in SDD suggests that forest fire impacts the snow-dominated hydrology consistently for at least ten years following fire (Gleason et al., 2019). This can be explained in majority by the constant deposition of $\mathrm{BC}$ on the snowpack as well as the continuous decrease in canopy cover due to initial fire-induced tree mortality and delayed tree mortality in years following fire. Fire-induced tree mortality and delayed tree mortality are complex issues caused by direct and indirect factors that cannot be represented by simple linear models (Hood et al., 2018). Factors such as past disturbance, stress, bark beetles, fungi, competition, season, and soil type all have different levels of impact on the issue of tree mortality (Hood and Bentz, 2007; Youngblood et al., 2009; Fettig et al., 2010; Das et $a l ., 2011)$, therefore making delayed tree mortality even more challenging to predict (Eidenshink et al., 2007). Patterns of fire-induced tree mortality and post-fire vegetation re-development effect the chance of forest regeneration and growth (Davis et al., 2018; Coop et al., 2020). These changes then effect future fire probability (Archibald et al., 2018). 
Recent advances in remote-sensing science have allowed for a more widespread investigation of some of the questions involving FFESA. One of those critical advances, the Moderate Resolution Imaging Spectroradiometer (MODIS) instrument, was launched aboard the Terra Satellite in December of 1999. The data from the Terra satellite became available starting late February of 2000. Additionally, a second MODIS instrument was launched aboard the Aqua satellite in May of 2002. MODIS has 36 bands with spatial resolution ranging from $250 \mathrm{~m}$ to $1-\mathrm{km}$. Many remote sensing products are derived from MODIS satellite imagery. Snow-cover and albedo products have been a large emphasis of these data products (Hall and Riggs, 2002), as snowfall and snowmelt events can happen rapidly, significantly changing the snow cover and albedo. Due to its daily temporal scale, MODIS provides an essential and effective means to monitor spatiotemporal changes in snow albedo over large areas (Klein and Stroeve, 2017).

Additionally, MODIS snow albedo products enhanced data acquisition and quality, with the ability to recognize and differentiate most snow and clouds (Hall and Riggs, 2002). The snow albedo snow-mapping algorithm was applied to provide global daily snow albedo for snow-covered areas. The current datasets acquiring snow cover and albedo specific measurements include MOD10A1 and MYD10A1. Additionally, related datasets provided by MODIS are currently collecting snow cover, including MOD10A1F, MYD10A1F, MYD10A2, MOD10A2, and multiple others. The temporal scale of these data ranges from 5 minutes to 1 month while the spatial scale is consistent at $500 \mathrm{~m}(0.05$ Deg). More so, there are data being collected using white-sky and black-sky albedo that can also be utilized for snow albedo acquisition. This now provides daily spatial data spanning back over two-decades anywhere on Earth (Hall et al., 2021). 


\section{Project Objectives}

Few studies have evaluated the magnitude of the spatio-temporal variability of the effects forest fires have on snow albedo relative to year-since-fire or burn severity. This paper examines the patterns and outcomes by observing MODIS daily snow albedo within specified forest fires and burn severities over temporal scales to analyze these effects. The analysis performed was utilized to better understand pre-fire vs. post-fire changes in LSA as well as the effect of delayed tree mortality in years following fire events. The post-fire snow albedo change (PFSAC) was analyzed to quantify changes in forest canopy cover in addition to snow albedo throughout multiple burn severities. It is essential to quantify these effects on snow albedo to understand the long-term and spatially distributed implications forest fires have on watershed snow hydrology as well as water resource availability. Specifically, we chose to focus on the following research questions:

1. What is the temporal effect of individual forest fires relative to burn severity on LSA?

2. What is the temporal variability relative to burn severity in the rate of PFSAC following a fire occurrence?

3. How do varying burn severity classifications effect post-fire snow albedo and forest density change and recovery periods?

4. Is there a common temporal period between different burn severity forests where LSA begins the recovery phase of returning to that of an unburned forest?

5. What are the hydrologic and climatic implications of PFSAC? 
The following hypotheses were tested based on our research questions and previous findings regarding FFESA:

- Hypothesis 1: While pre-fire LSA in high burn, moderate burn, and unburned forest will show no significant difference; post-fire high burn and moderate burn severity areas will have a significantly higher LSA than unburned forest areas due to landcover change and tree mortality.

- Hypothesis 2: The immediate rate of PFSAC (1 year following a fire) in high burn and moderate burn severity areas will be significantly greater than that of unburned forest and open areas due to landcover change and initial fire-induced tree mortality.

- Hypothesis 3: The rate of PFSAC will persist in burned areas for at least ten years following a fire occurrence (Gleason et al., 2019) due primarily to patterns of delayed tree mortality before showing signs of darkening due to forest regeneration and regrowth.

- Hypothesis 4: Post-fire LSA in burned areas will show similarities to that of open areas before recovering to that of an unburned forest at least ten to fifteen years after a fire occurrence.

A theoretical illustration is used to represent some of the hypotheses mentioned (Figure 1). The focus of this study falls on the immediate and persistent FFESA due to the availability of data. It is unsure whether enough temporal data is available to significantly test our final hypothesis. However, quantifying the immediate and persistent 
FFESA will provide significant information that will improve modeling and predictions for future use.

The subsequent sections focus on the study area of the project; present the in-depth remote sensing and statistical methods applied; present the key findings with regression models; and conclude with a thorough discussion and conclusion based on our findings.

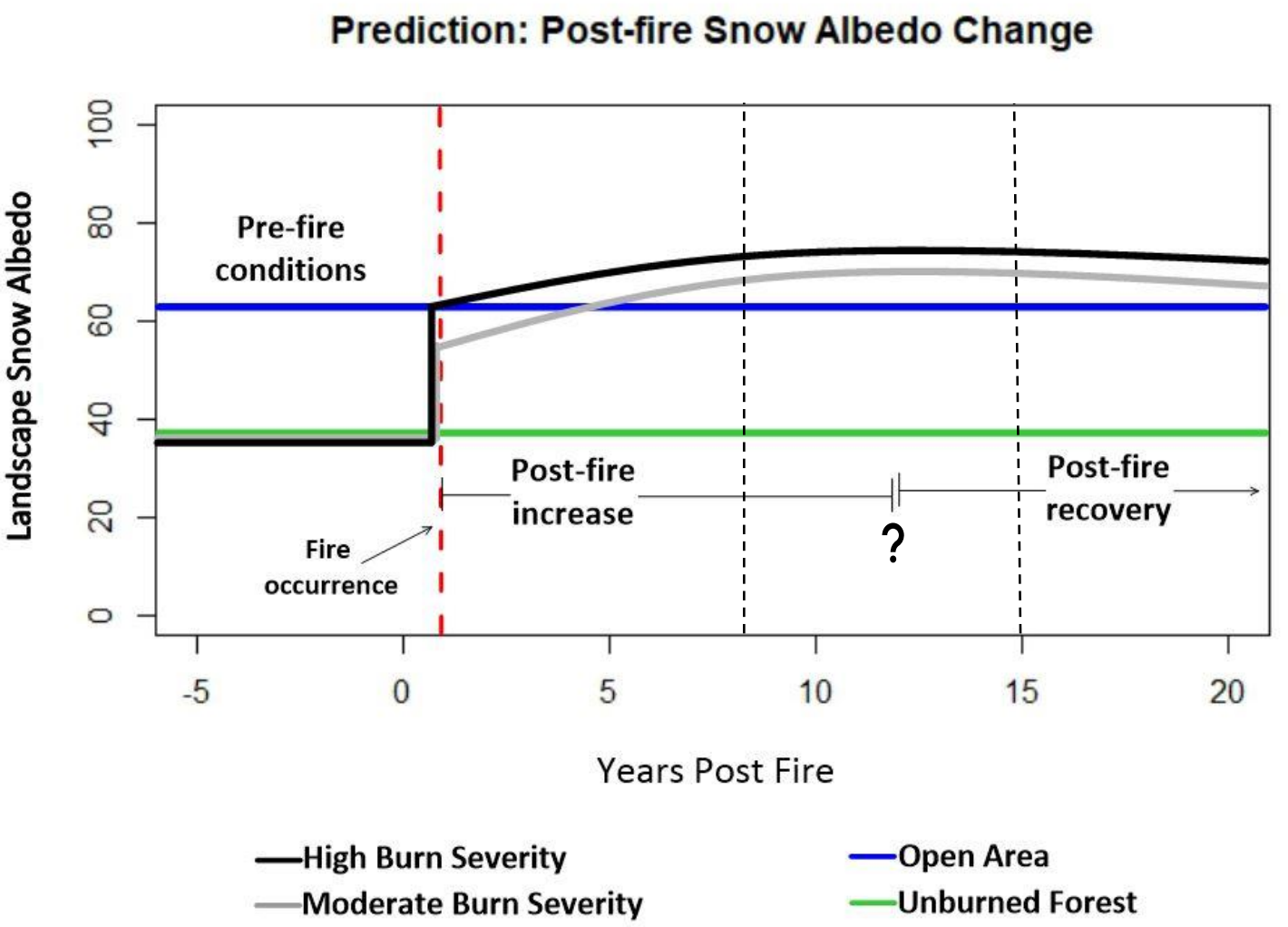

Figure 1. Hypothesized results of FFESA for each burn severity classification including pre-fire conditions, initial post-fire increase in LSA, and post-fire snow albedo recovery. The focus of the study is on the immediate and persistent FFESA. 


\section{Study Area}

We examined post-fire snow albedo change in a chronosequence of eight burned forests in the seasonal snow zone of western Wyoming burned from 2000 to 2018 from low to high severity. The study area extends around Jackson, Wyoming and across the Triple Divide, the headwaters of three major river systems, the Colorado, Columbia, and Missouri Rivers. The elevation of Jackson Hole Airport is 1,966 m. Cold season lasts for approximately 3.6 months, from November 19 to March 6, with average daily high temperatures below $35^{\circ} \mathrm{F}$. January 27 is recorded as the coldest day of the year, with an average low of $6^{\circ} \mathrm{F}$ and high of $25^{\circ} \mathrm{F}$ (Jackson Hole Airport).

This area is vital because it supplies much of the western US with readily available water and is essential for the continuous water sustainability. While as little as $37 \%$ of the entire precipitation in the western US falls as snow (Li et al., 2017), across this mountainous region, approximately $60-80 \%$ of precipitation falls as snow (Serreze et $a l ., 1999)$. The area is comprised of pine-dominated forests, predominately Lodgepole Pine (Pinus contorta) and Whitebark Pine (Pinus albicaulis), with history of regular and frequent forest fires across the season snow zone. The headwaters of these river systems begin high in the Rocky Mountains, where snow accounts for a large portion of the overall water accumulation that flows downstream into the Pacific Ocean, Gulf of California, and Gulf of Mexico. 


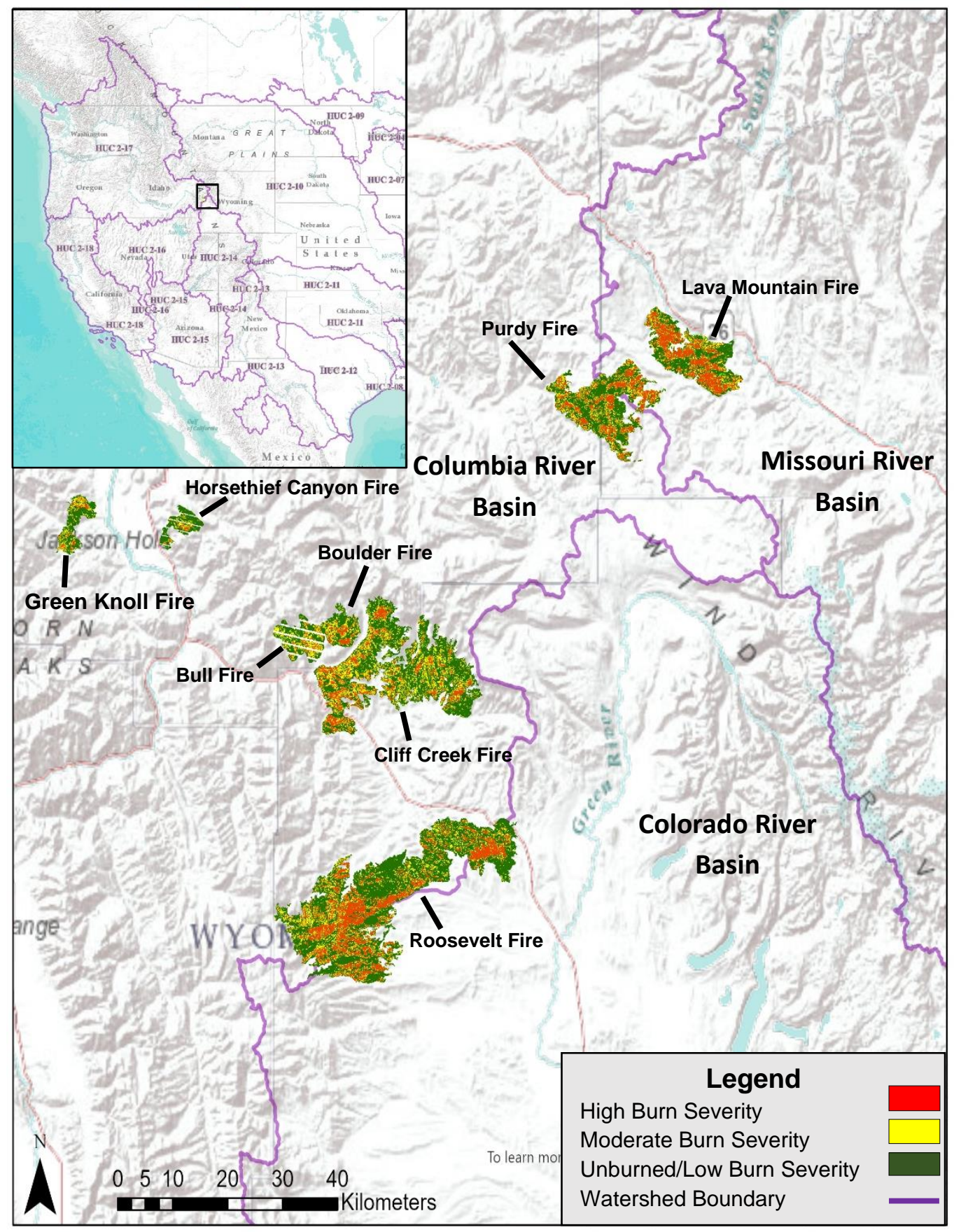

Figure 2. Fire site locations within the study area in western Wyoming with watershed boundary lines throughout the area. Top left: Western US with the study area focused on in the black box with the Columbia, Colorado, and Missouri River Basins labeled. 
The chronosequence of burned forests of progressing ages provide a study area with varying temporal features of post-fire impacts on LSA while reducing the spatial variability due to a relatively common forest structure and composition. The eight fires evaluated in this study occurred between 2000 and 2018 in and near the Hoback River Basin, and contain continuous and mixed patches of unburned, low, moderate, and high burn severity areas (Table 1$)$.

Table 1. Names and characteristics of the eight fire sites involved in the study of forest fire effects on snow albedo.

\begin{tabular}{c|ccccc}
\multicolumn{1}{c}{ Fire Name } & $\begin{array}{c}\text { Ignition } \\
\text { Date }\end{array}$ & $\begin{array}{c}\text { Burned } \\
\text { Area }\left(\mathbf{k m}^{2}\right)\end{array}$ & $\begin{array}{c}\text { Elevation } \\
(\mathbf{m})\end{array}$ & $\begin{array}{c}\text { Major River } \\
\text { System }\end{array}$ & $\begin{array}{c}\text { Average } \\
\text { Burn } \\
\text { Severity }\end{array}$ \\
\hline Boulder & $7 / 31 / 2000$ & 15.2 & 2240 & Columbia & Moderate \\
Green Knoll & $7 / 22 / 2001$ & 15.3 & 2144 & Columbia & Moderate \\
Purdy & $8 / 4 / 2006$ & 72.2 & 2804 & Columbia/Missouri & Moderate \\
Bull & $7 / 23 / 2010$ & 22.2 & 2164 & Columbia & Moderate \\
$\begin{array}{c}\text { Horsethief } \\
\text { Canyon }\end{array}$ & $9 / 8 / 2012$ & 11.3 & 2286 & Columbia & Low \\
$\begin{array}{c}\text { Lava } \\
\text { Mountain }\end{array}$ & $7 / 11 / 2016$ & 59.3 & 2432 & Missouri & Moderate \\
Cliff Creek & $7 / 17 / 2016$ & 146.2 & 2225 & Columbia & Moderate \\
Roosevelt & $9 / 15 / 2018$ & 248.9 & 2438 & Columbia/Colorado & Moderate
\end{tabular}




\section{Methods}

Our approach used a combination of remote sensing, downscaling, and statistical analysis to evaluate pre- vs. post-fire variability in LSA across a chronosequence of mixed severity burned forests in western Wyoming. Broadly, we evaluated LSA across temporal scales relative to burn severity, forest density, and years since fire. To isolate forest fire effects on snow albedo and omit interannual variability of snow accumulation and melt patterns, we normalized data from within the burn perimeter with data from the buffered area outside the burn perimeter. The 5-km buffer zones surrounding each fire perimeter were created as the spatial control variables. MODIS data products were the primary source for daily snow albedo as well as annual forest density to assess the spatiotemporal variability throughout the different fire locations. The data obtained from the MODIS products were evaluated on multiple spatio-temporal scales to develop a better understanding of FFESA. A list of the remote sensing products utilized during these analyses, as well as some of their features, is shown in Table 2.

\section{Remote Sensing Data}

A combination of multiple remote sensing tools were used to obtain and evaluate the necessary data for this study. Daily snow albedo and annual forest density data were acquired from Moderate Resolution Imaging Spectroradiometer (MODIS) datasets, forest fire areas and severity data were acquired from Monitoring Trends in Burn Severity (MTBS), and landcover data were acquired from National Land Cover Database (NLCD) records (Table 2). The forest fire areas, burn severities, and landcover classifications were used to create the burn severity classifications evaluated throughout the analysis: 
whole fire area, high burn severity, moderate burn severity, unburned forest, and open area. These areas were categorized as the burn severity classifications through the entirety of the analysis.

Table 2. Relevant remote sensing products used during this study.

\begin{tabular}{|c|c|c|c|}
\hline Quantity & Data Source & $\begin{array}{c}\text { Spatial } \\
\text { Resolution }\end{array}$ & Features \\
\hline $\begin{array}{l}\text { Burn Area } \\
\text { \& Severity }\end{array}$ & $\begin{array}{l}\text { Relative normalized } \\
\text { difference burn ratio } \\
\text { (RnDBR) from MTBS } \\
\text { (Eidenshink et al., 2007) }\end{array}$ & $30 \mathrm{~m}$ & $\begin{array}{l}\text { MTBS forest fire area and } \\
\text { severity derived from post-fire } \\
\text { changes to forest landscape } \\
(2000-2018)\end{array}$ \\
\hline $\begin{array}{l}\text { Snow } \\
\text { Albedo }\end{array}$ & $\begin{array}{l}\text { National Snow \& Ice Data } \\
\text { Center - MOD10A1 }\end{array}$ & $500 \mathrm{~m}$ & $\begin{array}{l}\text { MODIS/Terra daily, gridded } \\
\text { snow cover and snow albedo } \\
\qquad(2000-2019)\end{array}$ \\
\hline $\begin{array}{l}\text { Forest } \\
\text { Density }\end{array}$ & $\begin{array}{l}\text { Land Processes Distributed } \\
\text { Active Archive Center (LP } \\
\text { DAAC) - MOD44B }\end{array}$ & $250 \mathrm{~m}$ & $\begin{array}{c}\text { MODIS/Terra yearly } \\
\text { vegetation continuous fields } \\
(2000-2019)\end{array}$ \\
\hline $\begin{array}{l}\text { Landcover } \\
\text { Class }\end{array}$ & $\begin{array}{l}\text { National Land Cover Data Set } \\
\text { (NLCD) }\end{array}$ & $30 \mathrm{~m}$ & $\begin{array}{l}\text { NLCD 2001, 2008, 2011, } \\
2016 \text { used to classify } \\
\text { landcover conditions }\end{array}$ \\
\hline
\end{tabular}

Daily snow albedo was derived from the satellite images from MODIS MOD10A1 dataset; the MODIS/Terra Snow Cover Daily L3 Global 500m SIN Grid, Version 6. The data set contains daily, gridded snow cover and albedo derived from radiance data acquired by the MODIS instrument on board the Terra satellite (Hall and Riggs, 2016). The product output provided spatial pixels with values of 0 through 100 that represented snow albedo. MOD10A1 data was obtained on two 500 x $500 \mathrm{~m}$ spatial tiles that included all eight wildfire locations from January $1^{\text {st }}$ to April $30^{\text {th }}$ of each year. Data acquisition began on February 24, 2000 (the start of MOD10A1 data retrieval) and 
ended on April 30 ${ }^{\text {th }}, 2019$. We restricted data acquisition to these dates in order to evaluate predominately snow-covered winter and spring days. It was important to obtain data throughout these months because winter is driven by snow accumulation and spring is driven by snow ablation (Mott et al., 2018). The seasonal snow albedo is significantly different from winter to spring due to radiative heat forcing on snow (Keevallik and Tooming, 1996; Wang et al., 2015).

Forest density was derived from the satellite images from the MODIS MOD44B dataset; the MODIS/Terra Vegetation Continuous Fields (VCF) Yearly L3 Global $250 \mathrm{~m}$ SIN Grid, Version 6. The data set contains a global representation of surface vegetation cover as degrees of three ground cover components: percent tree cover, percent non-tree cover, and percent non-vegetated (bare). The VCF product provided a continuous and quantitative depiction of land surface cover with improved spatial features. MOD44B data was used to evaluate pre-fire vs. post-fire forest density. The data was obtained for the same spatial tiles as daily snow albedo. However, the spatial resolution of the data collected was 250 x $250 \mathrm{~m}$.

Forest fire area and burn severity data were collected from the MTBS database. This data was used to identify initial burn severity classifications within each burn area. These data were obtained through the 30-meter spatial resolution differenced Normalized Burn Ratio (dNBR) and Relativized differenced Normalized Burn Ratio (RdNBR) in MTBS. Each forest fire area and severity polygon were transformed to match the sinusoidal CRS of the MOD10A1 dataset. High and moderate burn severity areas were the primary areas of interest for evaluating the effects of forest fires on snow albedo since 
it was expected that these areas would see the greatest amount of post-fire LSA change. Therefore, areas classified as low burn severity by MTBS were combined with unburned forest areas into one burn severity classification. The NLCD landcover classifications were used to differentiate unburned forest and open areas. Excluding bodies of water and perennial ice and snow cover, each landcover classification was categorized as either forest or open area. All areas classified as deciduous, mixed, and coniferous forests were categorized as forest and all areas classified as developed, barren, shrubland, herbaceous, planted/cultivated, and wetland were categorized as open area (Appendix A; Figure 10). Burned areas were not differentiated by forest or open when classifying post-fire data.

In addition to the four burn severity classifications used to evaluate FFESA, buffer areas outside of the burn perimeter were identified to account for interannual variability and adjust for normal year-to-year fluctuations in snow accumulation and melt patterns. The buffer areas were constructed using the NLCD landcover data to categorize the land as either a forest buffer area or open buffer area. The buffer areas were classified exactly as the burned area; areas classified as deciduous, mixed, and coniferous forests were categorized as buffer forest and all areas classified as developed, barren, shrubland, herbaceous, planted/cultivated, and wetland were categorized as buffer open area. 


\section{MODIS Downscale}

MODIS at a $500 \mathrm{~m}$ and $250 \mathrm{~m}$ spatial resolution is too coarse relative to the spatial complexity and variability to evaluate the influence of burn severity on snow albedo following forest fire. In order to reduce the large uncertainties persistent with MODIS snow albedo data primarily due to the course spatial resolution and mixed pixels, we downscaled the broad scale snow albedo and forest density data using the $30 \mathrm{~m}$ burn severity data. To improve accuracy assessment of each MODIS pixel and the issue of mixed pixel uncertainty, we applied the weighted average of the 4-pixel neighboring values (Klein et al., 2003; Liang et al., 2008; Lindsay et al., 2015). The discrepancies, in areas of complex landcover patchiness, provide many issues and substantial uncertainty even after being transformed via downscaling methods (Chen, J. et al., 2019).

We used a method of resampling as the base procedure in performing an effective downscale of the MODIS data. The resampling evaluation we performed blended the spatial resolution of the Landsat data with the temporal frequency of the MODIS data to improve the spatio-temporal dynamics of our study. The MOD10A1 and MOD44B datasets were resampled via bilinear interpolation from the Landsat burn severity classifications using the values of the four nearest cell centers to determine the value of the resampled MOD10A1 and MOD44B datasets. We performed this procedure on every daily snow albedo and annual forest density measurement within each forest fire area and burn severity classification. 

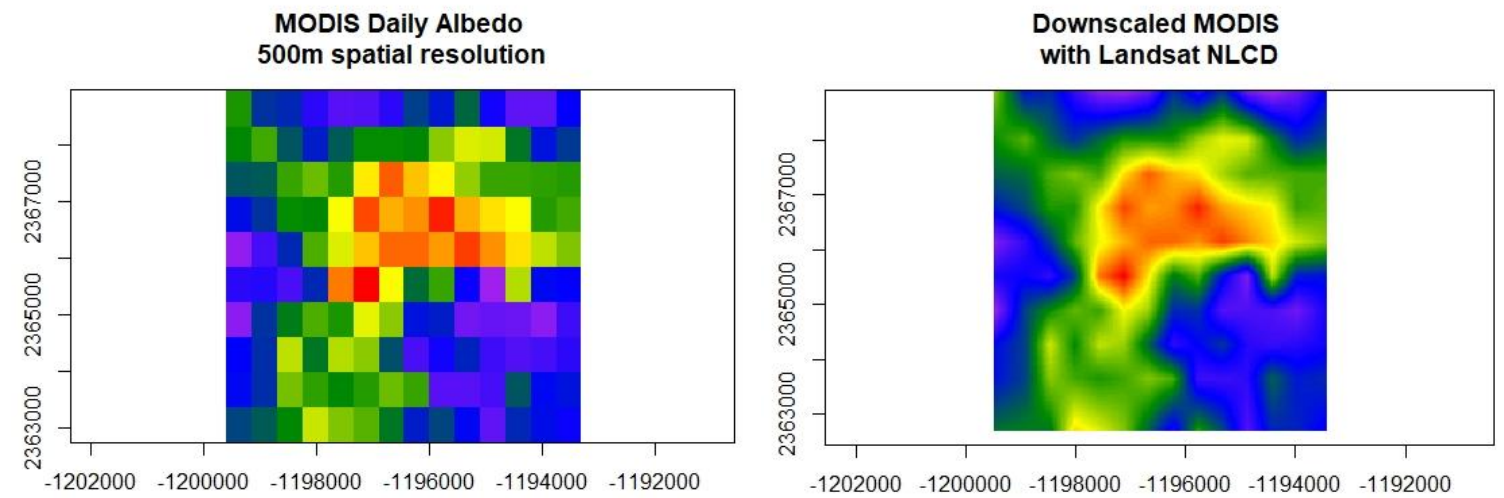

Downscaled MODIS within Green Knoll Fire

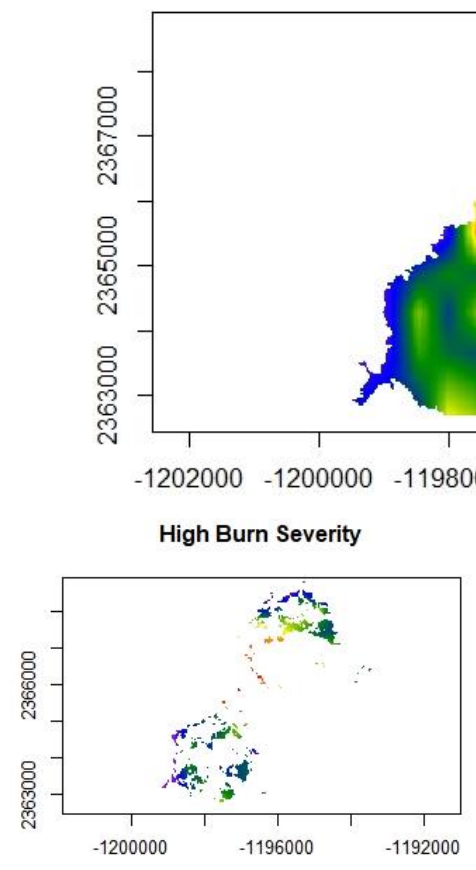

Snow Albedo
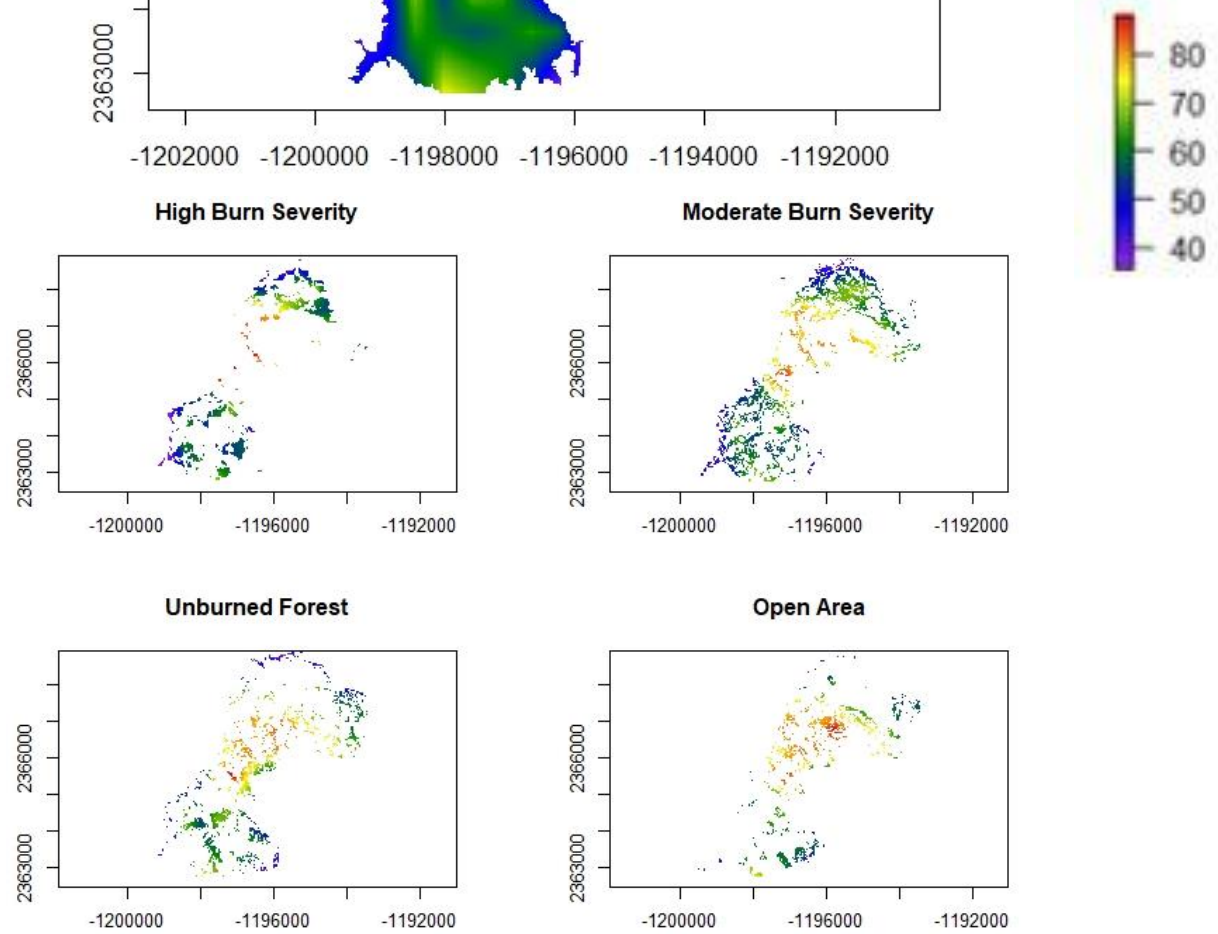

Figure 3. Example of the downscaling process complete for every daily snow albedo measurement and annual forest density measurement. The MODIS data was resampled, then cropped to fit the fire area, then evaluated for each burn severity classification. 


\section{Statistical Analysis}

We collected statistical measurements including average daily snow albedo value, maximum snow albedo, minimum snow albedo, standard deviation, and cell coverage percent was collected for each MOD10A1 measurement acquired. We chose to only evaluate measurements with greater than fifty percent cell coverage to ensure the corresponding cells were occupied with a majority of the presumed burn severity classification. In total, we evaluated 36,349 MODIS snow albedo measurements spread between eight fires and twelve burn severity classifications; 20,176 pre-fire measurements and 16,173 post-fire measurements. This included the buffer areas, if the buffer areas were excluded to only include measurements within the burn area, there was a total of 24,605 measurements spread between eight fires and eight burn severity classifications; 13,674 pre-fire measurements and 10,931 post-fire measurements. We used normalized LSA to omit the year-to-year weather fluctuations throughout the study area. We defined normalized LSA as the difference of the pre-fire buffer area LSA and the post-fire measurements. In order to keep the data consistent with pre-fire landscape conditions, we used the buffer forest area to normalize the high severity, moderate severity, and unburned forest areas, while the buffer open area was used to normalized the open area within the burn area.

We collected similar statistical measurements for the annual forest density data including, average forest density percent, maximum forest density percent, minimum forest density percent, standard deviation, and cell coverage percent. We acquired data for the same burn severity classifications as the daily snow albedo. The only difference in 
data collection for forest density was that it was done at an annual scale. Therefore, we evaluated twenty annual measurements of percent forest density for each burn severity classification within the forest fire area. There was a total of 160 forest density measurements taken in eight forest fire areas for a total of 1,280 forest density measurements for the entire analysis.

We evaluated the data with a combination of parametric and non-parametric approaches. We used Wilcoxon (Wilcox) rank-sum tests and one-way analysis of variance (ANOVA) tests to evaluate significant values for each fire, burn severity, and years post fire. Wilcox tests were used to determine significant differences among preand post-fire LSA and forest density measurements for each individual fire area as well as all combined. We used ANOVA tests to determine significant differences among burn severity classifications and years post fire for both LSA and forest density. In order to evaluate the results of the ANOVA tests, we used the post-hoc Tukey's honestly significant difference (HSD) tests to observe each comparison separately. Percent differences were calculated for all significant post-fire LSA measurements. A Generalized Additive Model (GAM) was developed for normalized LSA based on years post fire, forest density, and burn severity classification. The GAM was used to model the non-linear smooth functions of years post fire and forest density in order to capture the non-linearities throughout the data. The parametric coefficients are presented just as they would be in linear modeling. However, the smooth functions are presented in effective degrees of freedom, which represent the complexity of the smooth function. Multivariate linear regression models were used to quantify normalized LSA as a function of years 
post fire and forest density, relative to burn severity classification. Additionally, spline regression models were used to illustrate the significant segments of post-fire snow albedo change (PFSAC) where rates of increasing LSA significantly changed. The splines package in $\mathrm{R}$ was used for evaluating the different segments and representing them with a linear relationship. Since we were able to test the data for significant differences in PFSAC, manual knots were used at the years post fire that were found to be critical. The knots were placed at six years post fire and ten years post fire, which gave the linear spline regression three separate segments. To ensure each model's accuracy, the functions were partitioned with a $75-25$ split, such that $75 \%$ of the data was used to train the models and $25 \%$ of the data was used to test each model. ArcGIS Pro 2.7.0 and R Studio software version 1.2.5 (RStudio Team 2019) were used for all data analysis throughout the entirety of the study. Statistical relationships were tested with a significance level of 0.05 . 


\section{Results}

Annual Landscape Snow Albedo

In order to evaluate immediate and long-term shifts and temporal variability in post-fire LSA we investigated both daily and annual pre- and post-fire LSA (Figure 4). As expected, we observed an immediate increase in LSA $\left(p=1.95 \times 10^{-8}\right.$, mean increase $=6.6, \mathrm{sd}=12.8)$ the first winter following fire relative to pre-fire LSA.. Across all eight fires, LSA brightened by 33\%, and ranged from 8-39\% increase following forest fire (Table 3; $\mathrm{p}<2 \times 10^{-16}$, mean increase $=10.1$, sd $=11.9$ ), with approximately two-thirds of that total increase coming in the first winter after the fire event. The normalized prevs. post-fire LSA relative to burn severity for each individual fire (Appendix B; Figure 11) shows the overall increase observed in post-fire burn severity classifications. LSA continued to brighten for at least ten years post fire, across all fire events (Figure 6a), with the linear regression equation of LSA as a function of years post fire expressed in the bottom right of the plot. The increase in post-fire LSA relative to individual burned area (Appendix C; Figure 12) displayed the consistencies throughout each fire event. The observed decrease in post-fire forest density in burned forest areas was used to assist in explaining the increase in post-fire LSA. The decrease in forest density through each individual fire (Appendix D; Figure 13) displayed the drastic change from pre-fire forest density and post-fire forest density.

When winter and spring LSA were separated, we observed overall darker LSA in spring (Figure 5; averages marked by large circles). This was expected as well, due to warmer temperatures and normal melt patterns in the springtime. However, the difference 
between winter and spring LSA increased relative to each burn severity in post-fire measurements. While winter LSA showed a strong persistent increase in post-fire LSA (Figure 6b), spring LSA measurements were much darker and did not experience the same rate of increase (Figure 6c), suggesting a heightened effect due to past forest fires during the springtime snowmelt phase. 


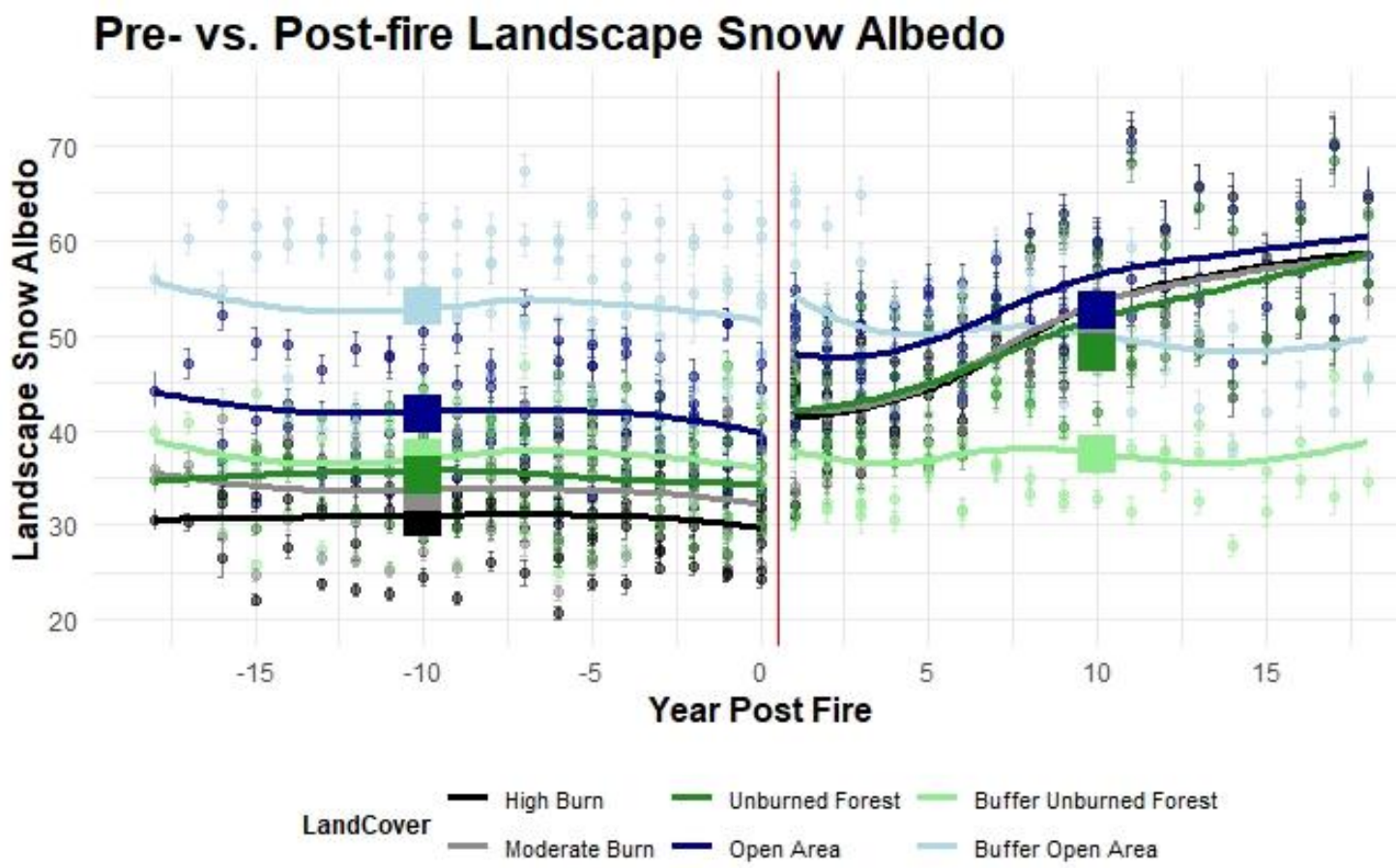

Figure 4. Pre-fire and post-fire LSA separated by high burn (black), moderate burn (gray), unburned forest (green), open area (blue), buffer forest (light green), and buffer open (light blue). The larger squares represent the pre-fire and post-fire averages.

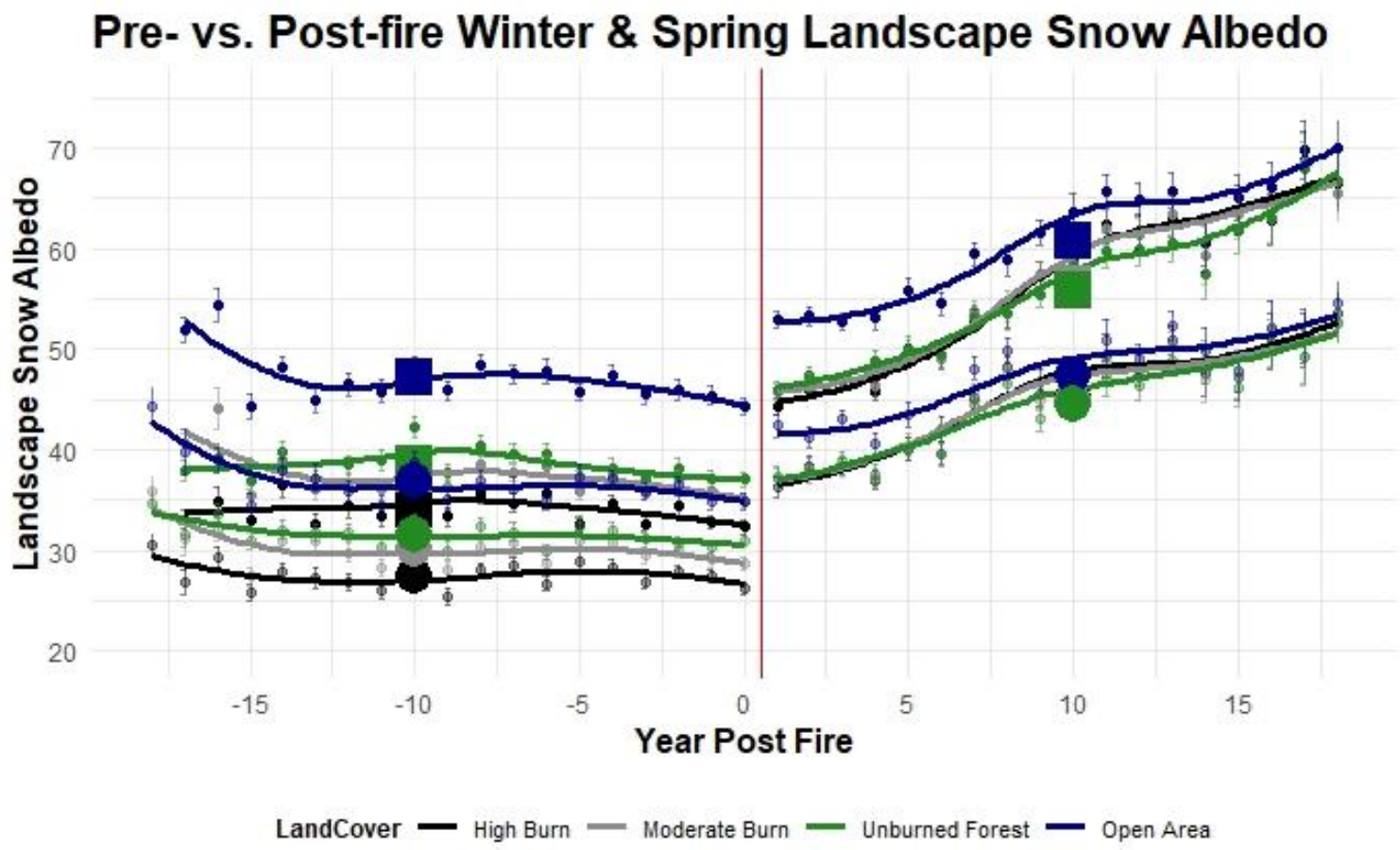

Figure 5. Winter \& Spring pre-fire and post-fire LSA separated by high burn (black), moderate burn (gray), unburned forest (green), and open area (blue). The large squares and circles represent the pre-fire and post-fire Winter and Spring mean LSA, respectively. 
Table 3. Pre-fire and post-fire LSA statistics for all eight fires separately including the mean difference and percent increase for each fire. $* * *=p<0.001$

\begin{tabular}{|c|c|c|c|c|c|c|c|c|}
\hline & $\begin{array}{c}\text { PRE- } \\
\text { FIRE } \\
\text { COUNT }\end{array}$ & $\begin{array}{l}\text { PRE- } \\
\text { FIRE } \\
\text { MEAN }\end{array}$ & $\begin{array}{c}\text { PRE- } \\
\text { FIRE SD }\end{array}$ & $\begin{array}{l}\text { POST- } \\
\text { FIRE } \\
\text { COUNT }\end{array}$ & $\begin{array}{l}\text { POST- } \\
\text { FIRE } \\
\text { MEAN }\end{array}$ & $\begin{array}{l}\text { POST- } \\
\text { FIRE SD }\end{array}$ & $\begin{array}{l}\text { MEAN } \\
\text { DIFF }\end{array}$ & $\begin{array}{c}\% \\
\text { INCREASE }\end{array}$ \\
\hline $\begin{array}{c}\text { BOULDER } \\
(2000)\end{array}$ & 99 & 36.83 & 9.21 & 4594 & 54.50 & 16.14 & $17.67 * * *$ & $39 \%$ \\
\hline $\begin{array}{c}\text { GREEN } \\
\text { KNOLL (2001) }\end{array}$ & 341 & 30.94 & 9.39 & 3742 & 44.28 & 13.18 & $13.34 * * *$ & $35 \%$ \\
\hline PURDY (2006) & 1629 & 33.24 & 9.72 & 2986 & 43.96 & 10.85 & $10.72 * * *$ & $28 \%$ \\
\hline BULL (2010) & 2498 & 37.64 & 11.99 & 1881 & 45.71 & 12.52 & $8.07 * * *$ & $19 \%$ \\
\hline $\begin{array}{l}\text { HORSETHIEF } \\
\text { CANYON } \\
(\text { (2012) }\end{array}$ & 2779 & 41.82 & 12.67 & 1405 & 45.49 & 12.95 & $3.67 * * *$ & $8.4 \%$ \\
\hline $\begin{array}{l}\text { CLIFF CREEK } \\
\text { (2016) }\end{array}$ & 4141 & 40.84 & 12.83 & 610 & 47.92 & 12.39 & $7.08 * * *$ & $16 \%$ \\
\hline $\begin{array}{c}\text { LAVA } \\
\text { MOUNTAIN } \\
\text { (2016) }\end{array}$ & 3949 & 31.85 & 9.69 & 698 & 45.16 & 10.06 & $13.31 * * *$ & $35 \%$ \\
\hline $\begin{array}{c}\text { ROOSEVELT } \\
\text { (2018) }\end{array}$ & 4740 & 43.16 & 13.86 & 257 & 50.33 & 12.74 & $7.17 * * *$ & $15 \%$ \\
\hline
\end{tabular}



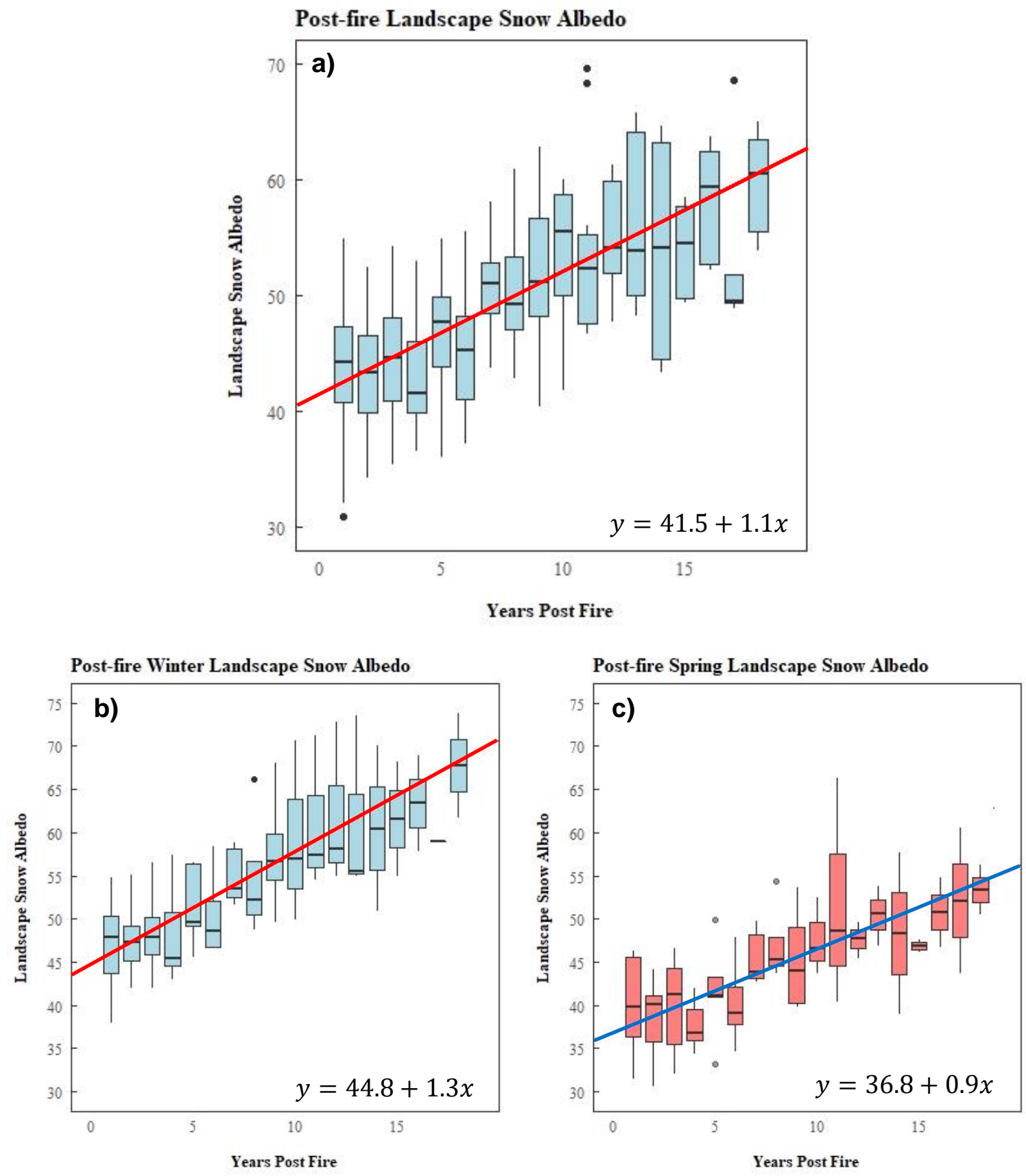

Figure 6. a) Post-fire annual LSA. b) Post-fire annual Winter LSA. c) Post-fire annual Spring LSA. Each boxplot represents the whole fire area. The linear regression line for each plot is presented in the bottom right of the plot. 
As expected, high burn severity and moderate burn severity classifications experienced highest difference in pre-fire vs. post-fire normalized LSA, undergoing a $44 \%$ and $36 \%$ increase, respectively (Table $\left.4 ; \mathrm{p}<2 \times 10^{-16}\right)$. Unexpectedly, unburned forest and open area classifications also experienced a high difference in pre-fire vs. postfire normalized LSA, undergoing a 32\% and 22\% increase, respectively (Table 4; $\mathrm{p}<2 \mathrm{x}$ $\left.10^{-16}\right)$. The data produced near-identical post-fire LSA results for high burn, moderate burn, and unburned forest classifications.

Table 4. Results from the daily normalized LSA Tukey HSD test based on the piecewise comparisons of burn severity classification in post-fire comparisons and pre-vs. post-fire comparisons. $* * *=p<0.001$.

\begin{tabular}{l|c|lc}
\multicolumn{1}{c}{ POST-FIRE } & PERCENT & \multicolumn{1}{c}{ PRE- VS. POST-FIRE } \\
COMPARISONS & INCREASE & $\begin{array}{c}\text { PERCENT } \\
\text { COMPARISONS }\end{array}$ & INCREASE \\
\hline OPEN-UNBURNED & $8.7 \% * * *$ & HIGH & $44 \% * * *$ \\
OPEN-HIGH & $8.4 \% * * *$ & MODERATE & $36 \% * * *$ \\
OPEN-MODERATE & $8.1 \% * * *$ & UNBURNED & $32 \% * * *$ \\
UNBURNED-HIGH & $0.3 \%$ & OPEN & $22 \% * * *$ \\
MODERATE-HIGH & $0.4 \%$ & & \\
UNBURNED-MODERATE & $0.7 \%$ & &
\end{tabular}

Annual Post-fire Snow Albedo Change

Annual LSA clearly displays a persisting increase for more than ten years following a fire, however, the rate of increase became progressively larger from years 610, which was most likely caused by delayed tree mortality and loss of dead branches. We took the five-year averages of PFSAC, separated by burn severity classification (Table 5; Figure 7) and calculated the rate of change for each stage of PFSAC. The fiveyear averages of PFSAC, separated by burn severity classification, for each individual fire (Appendix E; Figure 14) show the non-linearities in five-year periods. After the 
initial increase in LSA following a fire, LSA does not show a noteworthy difference until seven years post-fire $(p=0.0055)$ ranging from $11-19 \%$ increase by each burn severity classification. Years five and ten post-fire show a slightly greater increase in normalized LSA $(p=0.00019)$ ranging from $12-17 \%$ increase by each burn severity. The difference between years ten and fifteen post-fire signifiy stabalization in normalized LSA, ranging from $-0.6-3 \%$ change by each burn severity classification. This stabalization is representative of the LSA throughout the burned area becoming similar to that of a prefire open area approximately ten years following a fire event.

Table 5. Percentage PFSAC increase relative to each burn severity.

\begin{tabular}{|c|c|c|c|c|c|c|}
\hline & $\begin{array}{c}\text { PRE/1YR } \\
\text { POST }\end{array}$ & $\begin{array}{c}\text { 1YR/5YR } \\
\text { POST }\end{array}$ & $\begin{array}{c}\text { 1YR/7YR } \\
\text { POST }\end{array}$ & $\begin{array}{c}\text { 5YR/10YR } \\
\text { POST }\end{array}$ & $\begin{array}{c}\text { 10YR/15YR } \\
\text { POST }\end{array}$ & $\begin{array}{c}\text { PRE/15YR } \\
\text { POST }\end{array}$ \\
\hline HIGH BURN & $28 \%$ & $9.6 \%$ & $19 \%$ & $17 \%$ & $3.1 \%$ & $63 \%$ \\
\hline $\begin{array}{l}\text { MODERATE } \\
\text { BURN }\end{array}$ & $23 \%$ & $7.9 \%$ & $17 \%$ & $16 \%$ & $2.6 \%$ & $53 \%$ \\
\hline $\begin{array}{c}\text { UNBURNED } \\
\text { FOREST }\end{array}$ & $19 \%$ & $7.2 \%$ & $15 \%$ & $16 \%$ & $0.9 \%$ & $51 \%$ \\
\hline OPEN AREA & $15 \%$ & $3.2 \%$ & $11 \%$ & $12 \%$ & $-0.6 \%$ & $38 \%$ \\
\hline
\end{tabular}




\section{Post-Fire Snow Albedo Change}

Normalized to the Buffer Area

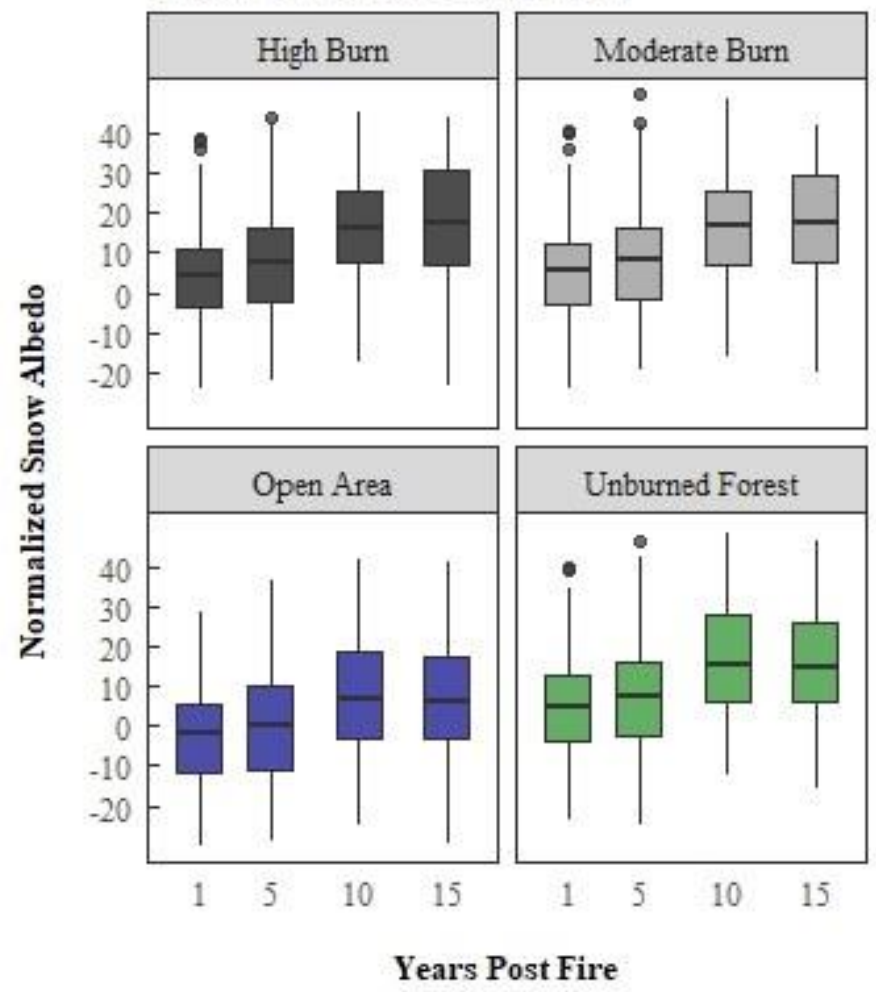

Figure 7. Normalized LSA results for post-fire snow albedo change. High burn (black), moderate burn (gray), and unburned forest (green) were normalized by taking the differenced LSA of the buffer forest area. Open area (blue) was normalized by taking the differenced LSA of the buffer open area.

Generalized Additive Model

We used smooth functions to represent the rate of PFSAC with a Generalized Additive Model (GAM) to capture normalized LSA as a function of years post fire (edf = $\left.6.2, \mathrm{p}<2 \times 10^{-16}\right)$, forest density (edf $\left.=2.9, \mathrm{p}=6.65 \times 10^{-07}\right)$, and burn severity classification (Figure 9). The GAM deviance explained $69.4 \%$ of the data, with a GCV of 23.582. We were able to interpret the normalized LSA visually from the GAM, however, due to it being a non-parametric analysis, we were not able to draw specific slopes from 
the predictors. We used the GAM to further observe and understand the relationship between the two predictor models (years post fire and forest density) with normalized LSA. Additionally, we used the GAM to assist in identifying the breaks in the PFSAC in order to evaluate the relationships with multivariate and linear spline regression models. Years post fire and normalized LSA was represented as a polynomial to the 6.23-degree, while forest density and normalized LSA was represented as a polynomial to the 2.93degree.
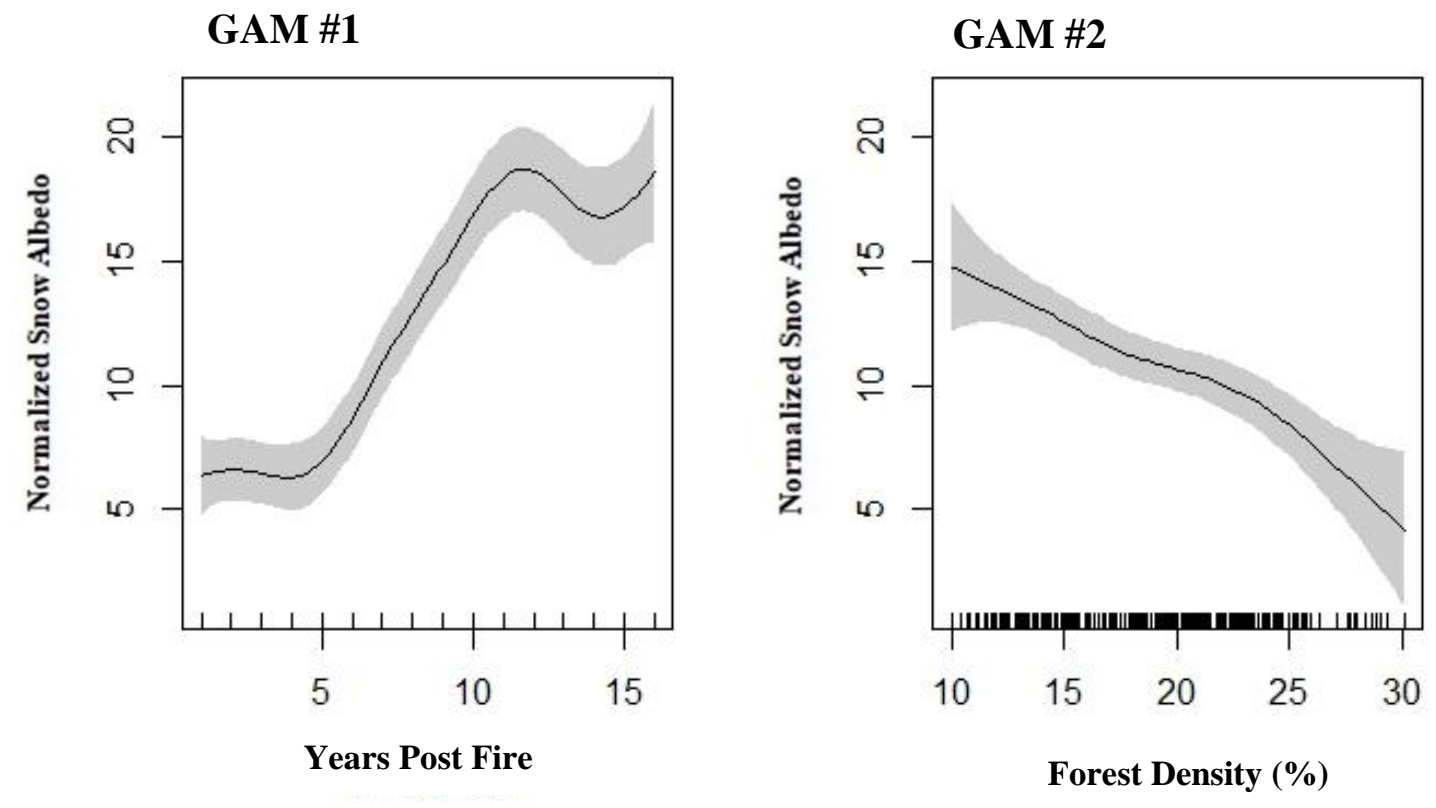

Figure 8. GAM representation of smooth functions (years post fire and forest density) as predictor variables with normalized LSA as the response variable. 
In order to quantify the rate of PFSAC, we developed a multivariate regression model of post-fire normalized LSA as a function of years post fire $\left(\mathrm{p}<2 \times 10^{-16}\right)$, forest density $\left(\mathrm{p}=1.08 \times 10^{-08}\right)$, and burn severity classification. The overall RMSE of the model was 4.90 (Table 6; $\mathrm{p}<2 \times 10^{-16}, \mathrm{R}^{2}=0.6755$ ).

Table 6. Results of the multivariate linear regression model for the rate of PFSAC as a function of years post fire and forest density, relative to each burn severity. $* * *=p<0.001$.

\begin{tabular}{l|ll} 
& \multicolumn{1}{l}{ COEFFICIENT } & STD ERROR \\
\hline YEARS POST FIRE & $1.0^{* * *}$ & 0.06 \\
FOREST DENSITY & $-0.4 * * *$ & 0.07 \\
BURN SEVERITY CLASSIFICATION & $12.2 * * *$ & 1.7 \\
(REFERENCE $=$ HIGH BURN SEVERITY) & & \\
MODERATE BURN SEVERITY & 0.2 & 0.8 \\
UNBURNED FOREST & 0.7 & 0.9 \\
OPEN AREA & $-10.1 * * *$ & 0.8 \\
\hline R-SQUARED & 0.6755 & \\
RESIDUAL STD ERROR & 4.955 & \\
DEGREES OF FREEDOM & 282 &
\end{tabular}

From here, we were able to quantify the multivariate regression model with an equation including all variables as:

Equation (5)

$$
y=12.2+1 x-0.4 f+0.2 \text { moderate }+0.7 \text { unburned }-10.1 \text { open }
$$

Where $\mathrm{y}$ is the normalized LSA, $\mathrm{x}$ is years post fire, and $\mathrm{f}$ is forest density. Years post fire and forest density represent continuous data, whereas the burn severity classifications are categorical, in that they are represented as a 1 or 0 depending on if we measured for that specific severity. 
While the multivariate linear regression model provided a strong foundation in quantifying the rate of PFSAC, explaining $67.55 \%$ of the variation with a residual standard error of 4.955, normalized LSA was not completely linear with respect to years post fire or forest density. In order to quantify normalized LSA while considering the stepwise non-linearity of the relationship, linear spline regression models were developed to measure the rate of PFSAC as a function of years post fire relative to burn severity classification (Table 7; Figure 10).

Table 7. Results of the linear spline regression models for normalized LSA as a function of years post fire. $*=p<0.05, * *=p<0.01, * * *=p<0.001$.

Equation (6)

$\begin{array}{cccccc}\text { MODEL EQUATION } & \text { RESIDUAL } & \text { DF } & \text { F- } & P- & R- \\ \text { STD } & & \text { STATISTIC } & \text { VALUE } & \text { SQUARED } \\ & \text { ERROR } & & & & \end{array}$

\begin{tabular}{|c|c|c|c|c|c|c|}
\hline $\begin{array}{c}\text { WHOLE } \\
\text { FIRE AREA }\end{array}$ & $\begin{array}{l}=1.96+0.66 x^{*}+1.96(x \\
-6)^{* *}-2.74(x-10)^{* * *}\end{array}$ & 6.387 & 260 & 60.21 & $\begin{array}{l}<2.2 x \\
10^{-16}\end{array}$ & 0.4031 \\
\hline $\begin{array}{l}\text { HIGH BURN } \\
\text { SEVERITY }\end{array}$ & $\begin{array}{l}=3.66+0.69 x+2.17(x \\
-6)^{*}-2.90(x-10)^{*}\end{array}$ & 4.989 & 62 & 29.58 & $\underset{12}{3.85} \times 10^{-}$ & 0.5688 \\
\hline $\begin{array}{c}\text { MODERATE } \\
\text { BURN } \\
\text { SEVERITY }\end{array}$ & $\begin{array}{l}=4.18^{*}+0.66 x+2.07(x \\
-6)^{*}-2.84(x-10)^{*}\end{array}$ & 4.742 & 62 & 29.6 & ${ }_{12}^{5.32} \times 10^{-}$ & 0.569 \\
\hline $\begin{array}{l}\text { UNBURNED } \\
\text { FOREST }\end{array}$ & $\begin{array}{l}=4.51^{*}+0.61 x+1.66(x \\
-6)-2.23(x-10)\end{array}$ & 6.008 & 62 & 13.84 & $<\frac{5.16 x}{10^{-7}}$ & 0.3721 \\
\hline OPEN AREA & $\begin{array}{l}=-4.53^{*}+0.68 x+1.92(x \\
-6)^{*}-2.99(x-10)^{*}\end{array}$ & 5.062 & 62 & 22.24 & $\underset{10}{6.78 \times 10^{-}}$ & 0.495 \\
\hline
\end{tabular}

Where the response variable is normalized LSA. The independent variable, years post fire, is represented by $\mathrm{x}$. The separated variables in the linear spline regression 
models represent the breaks at years six and ten post fire. The first variable (x) is used for calculating the normalized LSA for any year post fire. The second variable $(x-6)$ is only used when years post fire is greater than or equal to six. The third variable $(x-10)$ is only used when years post fire is greater than or equal to ten. This model signifies that for the total area effected by forest fire within this study, $40.31 \%$ of the variation in normalized LSA can be described by years post fire alone.

The results of each spline regression model describing the measured PFSAC vs. years post fire for all burn severity classifications are in Table 5. All 5 equations were found to be highly significant ( $\mathrm{p}$-value $<2.2 \times 10^{-16}-5.16 \times 10^{-7}$ ), explaining between $37.2-56.9 \%$ of the variation in PFLSA with years post fire.

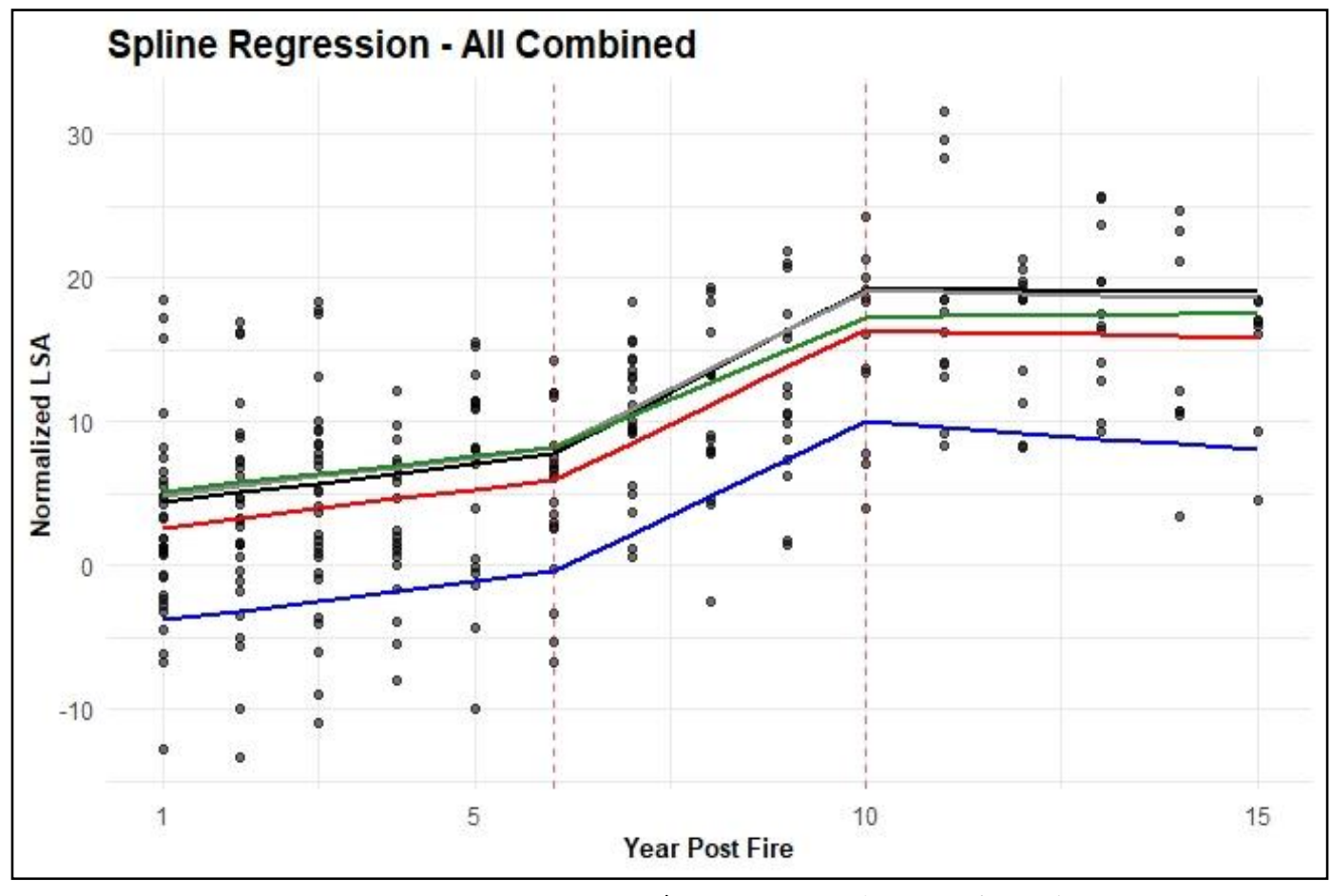

—Combined Fire Area —-High Burn Severity —Moderate Burn Severity —Unburned Forest —Open Area

Figure 9. Linear spline regression representation with two knots (three segments) to show the multiple levels of PFSAC relative to high burn (black), moderate burn (gray), unburned forest (green), open area (blue) and combined for whole fire area (red). 


\section{Discussion}

\section{Quantifying Post-fire Landscape Snow Albedo}

In all eight forest fire occurrences, MOD10A1 observed an immediate increase in post-fire LSA, initially brightening by $21 \%$ the first year following a fire, ranging from $15-28 \%$ relative to burn severity, and continued to increase for at least ten years following fire. These results were expected, as a decrease in forest density, due to initial and delayed tree mortality, caused an increase in exposure of the snow surfaces and direct shortwave radiation to reach the snowpack surface. Forest density and shortwave radiation were clear leading factors in post-fire LSA (Gleason et al., 2013; Zhuosen Wang et al., 2016). With the presence of LAP (predominately BC) deposited throughout the snowpack, past research suggested significant accelerated snowmelt and earlier SDD throughout forest fire areas (Gleason et al., 2019). Snow albedo decay has been measured to represent the increased radiative forcing on snow in burned forests (Gleason et al., 2016) immediately following fire occurrence, but the spatio-temporal variability of this process is still not well represented in hydrologic and climatic models.

We used a generalized additive model to further analyze the relationship between the two predictor models (years post fire and forest density) with normalized LSA. We used the GAM to assist in identifying the breaks in the PFSAC in order to evaluate the relationships with multivariate and linear spline regression models. Some of the complexities in measuring post-fire LSA were captured in the GAM. Although these relationships were not linear, the multivariate linear regression models we produced 
provided a measure of quantifying normalized LSA for post-fire burned areas as well as post-fire open areas. Due to these linear models being normalized, the model for burned areas, which included high burn, moderate burn, and unburned forest, showed the highest difference in initial change. This was expected for the high and moderate burn severity areas, but not for the unburned areas. The model for open area showed a smaller initial increase in normalized LSA, which was expected, as there should not have any significant landcover change in the open areas. However, it is almost certain that BC, brown carbon, and soil were transferred from burned areas and deposited in open areas due to natural weather variations. Although we were unable to successful detect levels of LAP in the MOD10A1 data, this would have had an effect on SSA, therefore potentially affecting post-fire LSA measurements.

We found that years post fire had a greater influence on increasing post-fire LSA than forest density had on decreasing post-fire LSA for at least ten years following a fire. It is clear forest density has an increased rate of influence once tree regeneration begins to singificant occur. In all eight fires, forest density was at its lowest approximately fifteen years following a fire before showing inidications of increasing in high burn, moderate burn, and unburned areas. As we past ten years following a fire, the linear regression models began losing accuracy, as LSA flattened out, possibly shifting to more of a recovery phase. For this reason, we quantified normalized LSA with a linear spline regression model, broken into three segments. While this model used years post fire as its sole predictor variable, there are visible breaks where the rate of PFSAC is significant. We used statistical tests to ensure the significance of the years at which we put the breaks 
into the model. Not including the significant change coming from the initial fire disturbance, year seven post-fire and year eleven post-fire provided singificant shifts in the normalized LSA measurements. We put the breaks at years six and ten post-fire, one year prior to both significant measurements, to measure the linear relationships within each segment (Figure 10). While the spline regression models provided strong results for the rate of PFSAC, years post fire, relative to burn severity classification, was used as the sole independent variable. These models provided more benefit for accurately predicting normalized LSA after ten years following a fire.

\section{Post-fire Snow Albedo Temporal Variation}

We acquired LSA measurements from MOD10A1 across a four-month period each year, in which the difference between pre-fire and post-fire LSA increases with time during the first ten years following a fire. We found an apparent connection between LSA and forest density. As mentioned, both MOD10A1 and MOD44B datasets observed a distinct shift following a fire occurrence. There is an increase in annual LSA immediately following the fire occurrence that persists for at least ten years before indication of leveling out. In addition, there is an immediate decrease in annual forest density that persists for approximately ten to twelve years before showing indications of leveling off, with possible signs of significant regeneration occurring fifteen years following a fire. This pattern of increasing LSA was likely influenced by delayed tree mortality and the continued loss of branches and standing dead boles (Bond-Lamberty and Gower, 2008) in the years following a fire. While signs of regeneration were visible in the MOD44B data approximately fifteen years following a fire, there may have been a delayed response of 
decreasing post-fire LSA back to pre-fire conditions due to MOD44B measuring on an annual temporal scale. Vegetation regeneration and regrowth most likely was most prevalent and visible in the late spring- and summertime. Past studies with MODIS products (Randerson et al., 2006; Jin, Randerson, Goulden, et al., 2012) suggest that the difference between pre-fire and post-fire spring- and summertime surface albedo increases with time during the first five to eight years following a fire. In snow dominated, mountainous areas, late-spring snow-cover may influence the appearance of vegetation recovery.

There was an observed period approximately between seven and ten years post fire (Figure 4) where the LSA in high burn, moderate burn, and unburned forest areas becomes brighter than the LSA in the buffer open area. This was unexpected, as the buffer open area was predicted to represent the brightest areas of measured LSA. However, when the buffer areas were constructed from the NLCD dataset, there were multiple landcover identifications classified as open area that might have made it significantly darker than an open meadow in the wilderness. For example, developed areas, which are typically impervious and dark surfaces, and shrublands, which were described as areas of two classes, one of which being shrubs no higher than three meters tall. Both landcover types were classified as buffer open areas in the study, while they have a probability to darken the LSA more than an open meadow. For this reason, it was possible for the LSA in the burned perimeter to appear brighter in the measured data than that of the buffer open area. 
Post-fire Snow Albedo Spatial Variation

When examining the individual forest fires, it was important for us to acknowledge the dynamics of pre-fire conditions as a function of landscape and ecological variability. While the forested areas were dominated by similar pinetree vegetation, there were many factors that made the results variable from fire to fire. Elevation and varying topography and aspect are important drivers that alter snow processes, including snow albedo. Landscape types were recorded in pre- and post-fire conditions, however elevation, topography, and aspect were not included in the analysis of MOD10A1 snow albedo.

Landscape dynamics following a forest fire event strongly effect LSA. The spatial heterogeneity caused by forest fires introduces new complexities influencing snow accumulation and ablation in burned forests. Throughout this study, we found the variability of daily post-fire LSA measurements increased when compared to that of the daily pre-fire LSA. The spatial scale of MOD10A1 made it difficult to differentiate the burn severity classifications in this matter. Therefore, we were not able to statistically differentiate between the post-fire LSA of high burn, moderate burn, and unburned forest areas. A contributing factor in this may have been the incorporation of low burned areas into our unburned classification, although low burned areas likely produce little forest damage, mostly affecting understory. However, MOD10A1 was able to capture the increased effect forest fires have on springtime snowmelt vs. winter accumulation. This suggests that, while forest fires may effect snow accumulation patterns, the largest effect 
they have may be present in springtime albedo due to presence of $\mathrm{BC}$, resulting in acclerated SDD, as found by Gleason et al., 2019.

At the large spatial resolution presented by the MOD10A1 pixels, there are key snow-forest processes that are occurring at the sub-pixel resolution that influenced the results of LSA that we most likely were not able to account for. This was the main purpose of downscaling the MODIS resolution. Pre-fire forest conditions are generally understood to be more homogenous, in that forested areas are dominated by vegetation and open area are more dominated by shrubland or grassland. However, the landscape mosaic becomes much more patchy and heterogenous following a forest fire, making it morey difficult to classify a single pixel with one solid burn severity classification. For instance, MODIS pixels assigned to a high burn severity designation most likely also contain patches of low or moderate burn severity, therefore, the snow albedo calculated from coarse spatial resolution MODIS pixels over high burn severity area is underrepresented and lower than it typically would be when determined by the finer spatial resolution of an instrument like Landsat-8 (Wang et al., 2016).

In addition, the unburned forest and open area displayed the least amount of change in normalized LSA (Figure 4), although it is important to note there was still an increase in normalized LSA following a fire event. While this was an unexpected observation, it suggests the level of uncertainty that went into this analysis, as it is expected that little or no change should occur to normalized LSA in unburned forest and open areas pre-fire vs. post-fire. This uncertainty is present due to multiple theories. Most likely, due to the idea that the decrease in forest density allows for more of the snow 
surface to be assessed by the coarse-grained MODIS satellite imagery, the entire burned area image would appear brighter. Another very likely possibility is due to coupling present between the different burn severity classifications, which also stems from the spatial resolution of MOD10A1. This provided an efficient technique in detecting any uncertainty of the spatio-temporal effect of forest fires on snow albedo.

\section{Landscape and Climate Effects on Snow Albedo}

In the Western US, forest fire activity is likely to continue an increasing trajectory in association with climate change throughout this century (Kitzberger et al., 2017;

Abatzoglou et al., 2019). Furthermore, in many areas throughout the seasonal snow zone, post-fire climate conditions are likely to become increasingly unfavorable to tree regeneration, even if seed sources are nearby (Liang et al., 2017; Kemp et al., 2019; Coop et al., 2020), having an exceedingly significant effect on overall seasonal snowpack. While these expected changes in fire and climate conditions have a large effect on snow patterns, there is a lot of uncertainty of the spatio-temporal effects they will pose on snow accumulation and ablation.

High severity burned areas are less likely to see complete forest regeneration, with a conversion to non-forest landscape probable (Kemp et al., 2019; Coop et al., 2020). Studies have suggested the increase in LSA following a forest fire, may be significant enough to neutralize the initial carbon release caused by the fire, and thus may not necessarily accelerate climate warming to a significant degree (Bala et al., 2007; Randerson et al., 2006), there are negative hydrologic implications of a forested area being converted to a non-forested area. While we were able to successfully quantify the 
spatio-temporal relationship between LSA and years post fire with forest density, there are complex measures influencing recovery after ten years following a fire. Post-fire landscape heterogeneity continues to increase with delayed tree mortality and regeneration rates, and it is unclear as to when, or if, LSA in a burned forest returns to the levels of pre-fire conditions. However, we need to acknowledge the uncertainties that come with the ability to effectively predict where, when, and how widespread post-fire forest conversions may be in the future. While most global climate models agree that temperatures will continue to rise this century, predicted changes in precipitation are variable (Knutti and Sedláček, 2013; Coop et al., 2020). This is likely to include continued uncertainties in predictions of future fire and forest regeneration models. However, any potential increases in precipitation are likely to be inadequate to balance out the effect of rising temperatures on fire activity (Flannigan et al., 2016) and declines in seasonal snowpack (Harpold and Molotch, 2015).

The largest changes in LSA values were found in the high and moderate severity areas, suggesting greater landscape changes played a critical role in the resulting LSA measurements. In addition, the pre-fire LSA values from the high $($ mean $=30.8, \mathrm{sd}=2.1)$ and moderate $($ mean $=33.5, \mathrm{sd}=1.9)$ burn severity areas had average LSA measurements lower than that of the unburned forest $($ mean $=35.1, \mathrm{sd}=1.9)$ area $($ Figure 4$)$. We expected that all three of these burn severity classification areas would have reported very similar pre-fire LSA, however, they were statistically significantly different. This suggests that the areas that burned most heavily in all eight fires were areas of slightly higher dense forests. The examination of forest density measurements from MOD44B 
clearly show areas classified as high burn severity (mean $=40.3$, sd $=1.6)$ had the greatest percentage of forest density, whereas moderate burn severity (mean $=35.4$, $\mathrm{sd}=$ 1.6) areas were slightly less covered, followed by areas of unburned forest (mean $=32.5$, sd $=1.9$ ) with less coverage. This signifies the importance of locating high density forests when examinating for burn probabilities. Song \& Lee, 2016 found that tree density of 0.45 represent a critical value for high burn severity probability. According to the MOD44B measurements in this study, the pre-fire averages in high burn severity areas fall closest to this critical threshold. In addition, the more dense the pre-fire forest is, the greater chance of larger changes in landcover after a forest fire occurrence, which influences burn severity classifications as well.

\section{Project Uncertainties}

While this study successfully reported multiple regression analysis of post-fire LSA and PFSAC for each burn severity classification, there are multiple errors and uncertainties to be acknowledged. MOD10A1, along with other remote sensing products, have limitations that are well-known within forest canopies and terrain shadows. Snow albedo detection in mountainous environments, like our study site, from remote sensing-based imagery can contain relatively large errors when measured in areas with steep slopes (Malmros et al., 2018). The snow-cover and snow albedo measurements within the MODIS products considers these limitations with its built-in snow-mapping algorithms, however, it is difficult to accurately correct for these errors without ground-based measurements. These methods are able to use the ratio of visible to near-infrared reflectance for the desired substance and work relatively well. However, the daily MODIS snow albedo product 
(Hall, Salomonson, \& Riggs, 2006) does not apply the same corrections that the MODIS bidirectional reflectance distribution function (BRDF) albedo products or white-sky and black-sky albedo products apply. This becomes primarily important in its assumption that forested areas are Lambertian reflectors, therefore having no BRDF corrections applied. This assumption does not identify the importance of forest density and canopy structure and does not account for shadows cast on neighboring vegetation, forest edge effects, or in forest gaps, which significantly changes the surface albedo, especially in snow-covered forests (Burakowski et al., 2015). Forest canopies are a reason for such great limitation because the snow beneath heavily dense canopies cannot be detected. While MODIS primarily uses the normalized difference snow index (NDSI) to accurately report snow albedo vs. land albedo, canopy cover and forest density play a critical role in darkening the apparent snow albedo in forested areas. This is an issue within the scope of this study because, while MOD44B forest density measurements change drastically in burned forest areas over space and time, it is difficult to determine the snow properties preceding the fire event without reasonable uncertainty. Without knowledge of these snow properties before the fire, it is difficult to compare these with the snow properties after the fire. While burned forests do not hold the same challenges as forest canopy cover and forest density, there is increased spatio-temporal variability in the snow cover and snow albedo (Gleason et al., 2016). Both fire area and burn severity show significant post-fire spatial heterogeneity at the landscape-level compared to pre-fire conditions. This adds more complexities in measuring both LSA and SSA. While the input of increased shortwave radiation and overall change in longwave radiation are driving forces in the radiative forcing on snow, the variability in SSA is highly affected by BWD and BC. MODIS Dust 
Radiative Forcing in Snow (MODDRFS) was developed (Painter et al., 2012) in order to capture and model snow reflectance data with LAP present in the snow cover. While this model has been proven to work with dust specific LAP (Painter et al., 2012), there has not been much work done in burned forest areas to validate it with $\mathrm{BC}$. While $\mathrm{BC}$ was not detectable at the landscape scale with MOD10A1, it is presumed in this study that its presence highly effects the snow accumulation and ablation throughout the burned area (Gleason et al., 2013; Gleason et al., 2019).

Additionally, there is uncertainty present when classifying the landcover and creating the buffer areas in this study. The $5 \mathrm{~km}$ buffer area surrounding the fire perimeter was calculated immediately outside the fire perimeter. This provides room for some potential mixing of buffer area pixel measurements within the fire perimeter boundary. While the buffer area was calculated from Landsat NLCD $30 \mathrm{~m}$ spatial resolution imagery, identical to that of MTBS fire area and burn severity imagery, the MODIS coupling issues might have been influenced by pixels within the fire areas. This would not highly influence the outcome, yet it would add another level of uncertainty when measuring LSA for the buffer areas. Identifying the various landcover types as "forest" or "open" areas may have also introduced some error into the buffer area measurements. While it was important to remove bodies of water from the data, I did not remove anything else. This allowed for large variability in the two classifications of the buffer area. For example, areas categorized as developed and shrubland in the NLCD data were classified as open areas, although shrubland was described as anything up to 3 $\mathrm{m}$ in height. Additionally, the deciduous and coniferous forest types differ on their 
overall effect on snow albedo, as deciduous trees lose their leaves and go dormant, leaving many more gaps than coniferous trees.

With the advances in remote sensing comes levels of uncertainty and error, MODIS data products are no exception. Studies have been done to compare the results of different MODIS products and have found MOD10A1 can be used to effectively characterize snow albedo trends (Wang et al., 2016; Malmros et al., 2018; Calleja et al., 2019). Throughout this project, there were noticeable levels of uncertainty within the data that we could not account for. Even after downscaling, it was apparent that there was some coupling present between the different burn severity classifications. This coupling error is likely due to "mixels", meaning a mixture of multiple burn severity classifications within one downscaled MODIS pixel. Wang et al. (2016) found that the albedo can range from 0.1 to 0.7 or higher within a single MODIS gridded pixel, especially if the grid has varied landcover types. When multiple burn severity classifications occupied the same MODIS gridded pixel, more error and uncertainty was present. After we completed the downscaling process, the MODIS spatial resolution was still taking landscape-level measurements, with plenty of error left unresolved. This may explain the similarities we found between the post-fire high burn, moderate burn, and unburned forest areas, as we could not completely differentiate the three classifications. The coupling effect could also be emphasized by low burned severity areas being incorporated into the unburned forest area. This would have an influence on separating FFESA based on burn severity classification as well. To minimize the uncertainty even more, the data was filtered to only include days where $50 \%$ or more of the cell coverage was unblemished. This was 
done to ensure the classified cells were filled with at least the majority of the assumed burn severity class. However, it was not possible to remove all uncertainty and coupling within the data before performing the analysis. 


\section{Conclusions}

We used a generalized additive model, multivariate linear regression models, and linear spline regression models to draw conclusions on MOD10A1-based LSA measurements as it relates to years since fire and forest density throughout a mix of varied burn severity classifications. Snow albedo forcing is spatially and temporally heterogeneous and depends on a variety of factors related to time since fire, fire severity, land cover, vegetation type, soils, topography, and seasonal variation. While we did not account for all these factors, it is important to understand some of the unexplained variation in the results. Forest fires have a significant effect on LSA and the non-linear rate of PFSAC by significantly decreasing forest density and increasing the direct exposure of the snowpack to incoming shortwave radiation. The PFSAC analysis suggests the rate of increasing LSA is most significant for the period between five and ten years following a fire event, before which the PFSAC is negligible possibly due to the transition between initial tree mortality and delayed tree mortality. After ten years post fire, the burned areas began a transition to the recovery phase, in which the rate of PFSAC becomes insignificant, signifying the stabilization of LSA after a forest fire, becoming more like that of an open area. This indicates that the first decade of PFSAC is dominated by persistent brightening due to the decrease in forest density and delayed tree mortality, most of which occurs after five years post fire event, before stabilizing and eventually beginning the process of darkening due to forest regeneration and regrowth. A process of continued monitoring of MODIS daily snow albedo is important in evaluating the recovery process. 
While this research study is not able to accurately measure the darkening effect of $\mathrm{BC}$ and BWD with MOD10A1, past research has shown that LAP a profound effect on snow albedo and ablation (Gleason et al., 2013). The analysis of LSA in the study was performed as an assessment to quantify PFSAC on a widespread scale for changes in watershed snow accumulation and ablation. Most global climate models agree that temperatures will continue to rise, causing seasonal snowpack will continue to decrease, resulting in earlier snowmelt and lower annual landscape albedo. As climate change persists, forest fires will continue to increase in intensity, size, frequency, and duration, impacting the environment and human life. In reference to the western US, the increase in forest fires and rising temperatures will continue to deplete seasonal snowpack, making water availability an increasing issue. It is important to recognize the spatio-temporal effect fires have on snowpack and water resources across the western US. Quantifying this effect will improve models where snow albedo is a critical part of estimating accumulation and ablation processes, while assessing water accessibility and vulnerability.

Future Steps

Satellite imagery analysis, both fine and coarse resolution, is essential in largescale investigations involving snow albedo and snow melt. Climate Normal is traditionally measured as the average over a 30 -year period. Snow albedo data will need to continue to be monitored and studied from MODIS in order to gain reliable climate normal estimations. The continuous improvements made to satellite technology allows deeper investigations into questions that have yet to be answered. While MODIS is set to 
expire here in the short term, the Visible Infrared Imaging Radiometer Suite (VIIRS) carries the capacity to replace it. Launched in 2011, VIIRS captures the same phenomena that MODIS currently tracks, acquiring visible and infrared imagery and radiometric measurements of Earth's atmosphere, land, and oceans. While this will continue to improve the temporal aspect of satellite imagery, it will also improve the spatial aspect, as VIIRS has slightly better spatial resolution, capturing snow cover and snow albedo data at 375-meter spatial resolution (Riggs et al., 2017). Work continues to be done in order to improve the representation of snow albedo in burned forest areas for applications in snow and land surface models. Changes in snow albedo and land cover in pine dominated forests persist for long periods of time following a fire. Long-term, fine-spatial resolution datasets are necessary to examine the post-fire vegetation characteristics and determine accurate snow albedo recovery. A key in doing this successfully is to better understand FFESA by integrating proper algorithms into these models to improve the predictions based on the impacts of topography, soil type and burn severity on the overall energy balance. Additionally, the use of airborne Lidar data, which provides high quality mapping of canopy density and height, would also substantially benefit the understanding of post-fire energy balance.

This study will assist in building spatio-temporal algorithms for the use in various burn severity areas. Doing further studies with more fine-grained remote sensing tools is necessary to ensure some of the uncertainty in this study. More work will need to be done in improving the representation of snow albedo decay on a daily scale for varying burn severities. While fresh snowfall drastically increases snow albedo, the deposition of LAP and the presence of BWD in burned forest areas is hypothesized to have a large effect on 
snow albedo decay for years following fire. This effect would, in theory, cause a rapid increase in snow albedo decay, leading to increased radiative forcing on snow, ultimately leading to accelerated snowmelt in burned forest areas. While accelerated snowmelt and earlier SDD in burned forest areas across the Western US has already been confirmed, there is still a need for improved snow albedo decay algorithms that become part of largescale hydrologic and climate models. In addition, continued work to obtain ground-based measurements is needed to confirm satellite-based imagery. Developing a hybrid-remote sensing modeling method for characterizing snow properties in burned forest areas, along with improving snow albedo decay algorithms in burned forest areas, will greatly improve the accuracy and precision in future land surface modeling applications. This will provide a vital pathway to characterizing, mapping, and modeling snow albedo and FFESA on a global scale, furthering our understanding of the spatio-temporal variability of post-fire impacts on hydrology, and integrating the appropriate variables and remote sensing data into hydrology models. This will drive development of accurate, real-time information of forest fire effects to water resource vulnerability and availability for land managers and policy makers. 


\section{References}

Abatzoglou, J.T. (2011), Influence of the PNA on declining mountain snowpack in the Western United States. International Journal of Climatology, 31, 1135-1142.

Abatzoglou, J. T., Williams, A. P., \& Barbero, R. (2019). Global emergence of anthropogenic climate change in fire weather indices. Geophysical Research Letters, 46, 326- 336. https://doi.org/10.1029/2018GL080959

Amaral, T., C. P. Wake, J. E. Dibb, E. A. Burakowski, and M. Stampone (2017), A simple model for predicting snow albedo decay using observations from the Community Collaborative Rain, Hail, and Snow-Albedo (CoCoRAHS-Albedo) Network, Journal of Glaciology.

Archibald, S., Lehmann, C.E.R., Gomez-Dans, J.L., Bradstock, R.A., 2013. Defining pyromes and global syndromes of fire regimes. Proceedings of the National.

Bair, E. H., Rittger, K., Skiles, S. M. K., \& Dozier, J. (2019). An examination of snow albedo estimates from MODIS and their impact on snow water equivalent reconstruction. Water Resources Research, 55, 78267842. https://doi.org/10.1029/2019WR024810

Bala, G., Caldeira, K., Wickett, M., Phillips, T. J., Lobell, D. B., Delire, C., \& Mirin, A. (2007). Combined climate and carbon-cycle effects of large-scale deforestation. Proceedings of the National Academy of Sciences of the United States of America, 104(16),6550-6555. http://dx.doi.org/10.1073/pnas.0608998104.

Barnett, T., Adam, J. \& Lettenmaier, D. Potential impacts of a warming climate on water availability in snow-dominated regions. Nature 438, 303-309 (2005). https://doi.org/10.1038/nature04141

Barnhart, T. B. et al. Snowmelt rate dictates streamflow. Geophys. Res. Lett. 43,80068016 (2016).

Berghuijs, W., R. Woods, and M. Hrachowitz (2014), A precipitation shift from snow towards rain leads to a decrease in streamflow, Nature Climate Change, 4(7), 583586, doi:10.1038/nclimate2246.

Bond-Lamberty, B., \& Gower, S. T. (2008). Decomposition and fragmentation of coarse woody debris: Re-visiting a boreal black spruce chronosequence. Ecosystems, 11(6), 831-840. http://dx.doi.org/10.1007/s10021-008-9163-y. 
Burles, K., \& Boon, S. (2011). Snowmelt energy balance in a burned forest plot, Crowsnest Pass, Alberta, Canada. Hydrological Processes, 25(19), 3012-3029.

Buytaert, W., Cuesta-Camacho, F., and Tobon, C. (2011), Potential impacts of climate change on the environmental services of humid tropical alpine regions, Global Ecology and Biogeography, 20(1), 19-33.

Calleja, J., Corbea-Perez, A., Fernandez, S., Recondo, C., Peon, J., and Angel de Pablo, M. (2019). Snow Albedo Seasonality and Trend from MODIS Sensor and Ground Sata at Johnsons Glacier, Livingston Island, Maritime Antarctica. Sensors 2019, 19, 3569; doi:10.3390/s19163569.

Coons, L.P. \& Nolin, Anne \& Gleason, Kelly \& Mar, E.J. \& Rittger, Karl \& Roth, Travis $\&$ Painter, Thomas. (2014). Seeing the Snow Through the Trees: Toward a Validated Canopy Adjustment for Satellite Snow-Covered Area. Remote Sensing of the Terrestrial Water Cycle. 199-213. 10.1002/9781118872086.ch12.

Delaney, I., Kaspari, S., and Jenkins, M. (2015). Black carbon concentrations in snow at Tronsen Meadow in Central Washington from 2012 to 2013: Temporal and spatial variations and the role of local forest fire activity. Journal of Geophysical Research: Atmospheres, 120(18), 9160-9172.

Dennison, P. E., Brewer, S.C., Arnold, J.D., and Moritz, M.A. (2014), Large wildfire trends in the western United States, 1984-2011, Geophysical Research Letters, 41, 2928-2933.

Derksen, C., and R. Brown (2012), Spring snow cover extent reductions in the 20082012 period exceeding climate model projections, Geophysical Research Letters, 39, L19504, doi:10.1029/2012GL053387.

Dingman, S. L., (2002), Physical Hydrology, 2nd Edition, Prentice Hall.

Dozier, J., Green, R.O., Nolin, A.W., and Painter, T.H. (2009), Interpretation of snow properties from imaging spectrometry, Remote Sensing of Environment, 113, S25-S37.

Eidenshink, J., Schwind, B., Brewer, K., Zhu, Z., Quayle, B., \& Howard, S. (2007), A project for monitoring trends in burn severity. Fire Ecology, 3 (1), 3-21.

Elizabeth A. Burakowski, Scott V. Ollinger, Lucie Lepine, Crystal B. Schaaf, Zhuosen Wang, Jack E. Dibb, David Y. Hollinger, JiHyun Kim, Angel Erb, Mary Martin, Spatial scaling of reflectance and surface albedo over a mixed-use, temperate 
forest landscape during snow-covered periods, Remote Sensing of Environment, Volume 158, 2015, Pages 465-477, ISSN 0034-4257, https://doi.org/10.1016/j.rse.2014.11.023.

Flanner, M., K. Shell, M. Barlage, D. Perovich, and M. Tschudi (2011), Radiative forcing and albedo feedback from the Northern Hemisphere cryosphere between 1979 and 2008, Nature Geoscience, 4(3), 151-155, doi:10.1038/NGEO1062.

Gergel, D.R., Nijssen, B., Abatzoglou, J.T. et al. Effects of climate change on snowpack and fire potential in the western USA. Climatic Change 141, 287-299 (2017). https://doi.org/10.1007/s10584-017-1899-y

Gleason, K.E., McConnell, J.R., Arienzo, M.M. et al. Four-fold increase in solar forcing on snow in western U.S. burned forests since 1999. Nat Commun 10, 2026 (2019). https://doi.org/10.1038/s41467-019-09935-y.

Gleason, K. E., and Nolin, A. W. (2016), Charred forests accelerate snow albedo decay: parameterizing the post-fire radiative forcing on snow for three years following fire. Hydrological Processes, 30(21), 3855-3870.

Gleason, K. E., Nolin, A. W., and Roth, T. R. (2013), Charred forests increase snowmelt: Effects of burned woody debris and incoming solar radiation on snow ablation. Geophysical Research Letters, 40(17), 4654-4661.

Hadley, O.L. and Kirchstetter, T.W., 2012. Black-carbon reduction of snow albedo. Nature Climate Change, 2(6), pp.437-440.

Hall, D.K. and Riggs, G.A. (2007) Accuracy assessment of the MODIS snow products. Hydrological Processes 21, 1534-1547.

Hall, D. K. and G. A. Riggs. 2016. MODIS/Terra Snow Cover Daily L3 Global 500m SIN Grid, Version 6. Snow Albedo. Boulder, Colorado USA. NASA National Snow and Ice Data Center Distributed Active Archive Center. doi: https://doi.org/10.5067/MODIS/MOD10A1.006. August 18, 2020.

Hall, D. K., V. V. Salomonson, and G. A. Riggs. (2006) MODIS/Terra Snow Cover Daily L3 Global 500m Grid. Version 5. Boulder, Colorado USA: National Snow and Ice Data Center.

Harpold, A. A., and N. P. Molotch (2015), Sensitivity of soil water availability to changing snowmelt timing in the western U.S., Geophys. Res. Lett., 42, 80118020, doi:10.1002/2015GL065855. 
Houghton, J. T., L. G. M. Filho, B. A. Callander, N. Harris, A. Kattenberg, and K.

Maskell, Climate Change 1995: The Science of Climate Change,

Intergovernmental Panel on Climate Change, Cambridge University Press, Cambridge, GB, 1996.

Jeppe K. Malmros, Sebastian H. Mernild, Ryan Wilson, Torbern Tagesson, Rasmus Fensholt, Snow cover and snow albedo changes in the central Andes of Chile and Argentina from daily MODIS observations (2000-2016), Remote Sensing of Environment, Volume 209, 2018, Pages 240-252, ISSN 0034-4257, https://doi.org/10.1016/j.rse.2018.02.072.

Jin, Y., Randerson, J. T., Goulden,M. L., \& Goetz, S. J. (2012a). Post-fire changes in net shortwave radiation along a latitudinal gradient in boreal North America. Geophysical Research Letters, 39(13), 1-7. http://dx.doi.org/10.1029/2012GL051790.

Jin, Y., Randerson, J. T., Goetz, S. J., Beck, P. S. aA, Loranty,M. M., \& Goulden,M. L. (2012b). The influence of burn severity on postfire vegetation recovery and albedo change during early succession in North American boreal forests. Journal of Geophysical Research - Biogeosciences, 117(1), 1-15. http://dx.doi.org/10.1029/2011JG001886.

John Townsend, Charlene DiMiceli - University of Maryland and MODAPS SIPS NASA. (2015). MOD44B MODIS/Terra Vegetation Continuous Fields Yearly L3 Global 500m SIN Grid. NASA LP DAAC. http://doi.org/10.5067/MODIS/MOD44B.006

Jonathan D Coop, Sean A Parks, Camille S Stevens-Rumann, Shelley D Crausbay, Philip E Higuera, Matthew D Hurteau, Alan Tepley, Ellen Whitman, Timothy Assal, Brandon M Collins, Kimberley T Davis, Solomon Dobrowski, Donald A Falk, Paula J Fornwalt, Peter Z Fulé, Brian J Harvey, Van R Kane, Caitlin E Littlefield, Ellis Q Margolis, Malcolm North, Marc-André Parisien, Susan Prichard, Kyle C Rodman, Wildfire-Driven Forest Conversion in Western North American Landscapes, BioScience, Volume 70, Issue 8, August 2020, Pages 659673, https://doi.org/10.1093/biosci/biaa061

Jolly, W., Cochrane, M., Freeborn, P. et al. Climate-induced variations in global wildfire danger from 1979 to 2013. Nat Commun 6, 7537 (2015). https://doi.org/10.1038/ncomms8537

Keeley, J.E. (2009), Fire intensity, fire severity and burn severity: a brief review and suggested usage, International Journal of Wildland Fire, 18, 116-126. 
Kemp, K. B., Higuera, P. E., Morgan, P., and Abatzoglou, J. T. 2019. Climate will increasingly determine post-fire tree regeneration success in low-elevation forests, Northern Rockies, USA. Ecosphere 10(1):e02568. 10.1002/ecs2.2568

Kitzberger T, Falk DA, Westerling AL, Swetnam TW (2017) Direct and indirect climate controls predict heterogeneous early-mid $21^{\text {st }}$ century wildfire burned area across western and boreal North America. PLoS ONE 12(12): e0188486. https://doi.org/10.1371/journal.pone.0188486

Knutti, Reto \& Sedlacek, Jan. (2012). Robustness and Uncertainties in the New CMIP5 Climate Model Projections. submitted to Nature Climate Change. 3. 10.1038/nclimate1716.

Kolberg, S., and L. Gottschalk (2010), Interannual stability of grid cell snow depletion curves as estimated from MODIS images, Water Resour. Res., 46, W11555, doi:10.1029/2008WR007617.

Krawchuk, M.A., Moritz, M.A., Parisien, M.-A., Van Dorn, J., Hayhoe, K., 2009. Global Pyrogeography: the Current and Future Distribution of Wildfire. PLoS ONE 4, e5102. https://doi.org/10.1371/journal.pone.0005102.

Li, D., M. L. Wrzesien, M. Durand, J. Adam, and D.P. Lettenmaier (2017), How much runoff originates as snow in the western United States, and how will that change in the future?, Geophys. Res. Lett., 44, 6163-6172, doi:10.1002/2017GL073551.

Lettenmaier, D. P., D. Alsdorf, J. Dozier, G. J. Huffman, M. Pan, and E. F. Wood (2015), Inroads of remote sensing into hydrologic science during the WRR era, Water Resources Research, 51(9), 7309-7342, doi:10.1002/2015WR017616.

Littell, J.S., McKenzie, D., Peterson, D.L., Westerling, A.L., 2009. Climate and wildfire area burned in western U.S. ecoprovinces, 1916-2003. Ecological Applications 19, 1003-1021. https://doi.org/10.1890/07-1183.1.

Mankin J. S., D. Viviroli, D. Singh, A. Y. Hoekstra, and N. S. Diffenbaugh (2015), The potential for snow to supply human water demand in the present and future. Environmental Research Letters, 10(11), 114016, doi:10.1088/17489326/10/11/114016.

Marks D, Dozier J. 1992. Climate and energy exchange at the snow surface in the alpine region of the Sierra Nevada: 2. Snow cover energy balance. Water Resources Research 28: 3043-3054. 
Miller, J.D., Knapp, E., Key, C., Skinner, C., Isbell, C., Creasy, R.M., and Sherlock, J. (2009). Calibration and validation of the relative differenced Normalized Burn Ratio (RdNBR) to three measures of fire severity in the Sierra Nevada and Klamath Mountains, California, USA. Remote Sensing of Environment, 113, 645 -656, doi: 10.1016/j.rse.2008.11.009.

Miller, J. D., and A. E. Thode. (2007) Quantifying burn severity in a heterogeneous landscape with a relative version of the delta Normalized Burn Ratio (dNBR). Remote Sensing of Environment, 109, 66-80, doi:10.1016/j.rse.2006.12.006.

Mote, P., Hamlet, A., and Salathé, E.: Has spring snowpack declined in the Washington Cascades?, Hydrol. Earth Syst. Sci., 12, 193-206, https://doi.org/10.5194/hess-12193-2008, 2008.

Mote, P.W., Li, S., Lettenmaier, D.P. et al. Dramatic declines in snowpack in the western US. npj Clim Atmos Sci 1, 2 (2018). https://doi.org/10.1038/s41612-018-0012-1

Nolin, A. W., Dozier, J., and Mertes, L.A.K. (1993). Mapping alpine snow using a spectral mixture modeling technique. Annals of Glaciology, 17, $121-124$.

Nolin, A.W. (2010) Recent advances in remote sensing of seasonal snow. Journal of Glaciology, 56(200), 1141-1150.

O’Neill, A. D. J., and Gray, D. M., 1973: "Solar Radiation Penetration through Snow," Intern. Assoc. Hydrologic Sci. Publ. No. 107, Vol. 1, pp. 227-241.

Painter, T. H., Bryant, A. C., and Skiles, S. M. (2012), Radiative forcing by light absorbing impurities in snow from MODIS surface reflectance data, Geophysical Research Letters, 39.

Painter, T. H., Deems, J. S., Belnap, J., Hamlet, A. F., Landry, C. C., and Udall, B. (2010), Response of Colorado River runoff to dust radiative forcing in snow, PNAS, 107(40), 17125-17130.

Painter, T. H., K. Rittger, C. McKenzie, P. Slaughter, R. E. Davis, and J. Dozier (2009), Retrieval of subpixel snow covered area, grain size, and albedo from MODIS, Remote Sensing of Environment, 113, 868-879.

Pederson, G. T., Betancourt, J. L., and McCabe, G. J. (2013), Regional patterns and proximal causes of the recent snowpack decline in the Rocky Mountains, US, Geophysical Research Letters, 40, 1-6, doi:10.1002/grl.50424. 
Pierce, D. W., and D. R. Cayan (2013), The uneven response of different snow measures to human-induced climate warming, Journal of Climate, 26(12), 4148-4167, doi:10.1175/jcli-d-12-00534.1.

Randerson, J. T., Liu, H., Flanner, M. G., Chambers, S. D., Jin, Y., Hess, P. G., ... Zender, C. S. (2006). The impact of boreal forest fire on climate warming. Science (New York, N.Y.), 314(5802), 1130-1132. http://dx.doi.org/10.1126/science.1132075.

Riggs, G. A., D. K. Hall, and M. O. Román. 2017. Overview of NASA's MODIS and VIIRS snow-cover Earth System Data Records. Earth System Science Data Discussions. doi:10.5194/essd-2017-25.

Rittger, K., Painter, T.H., Dozier, J. (2013), Assessment of methods for mapping snow cover from MODIS. Advances in Water Resources, 51, 367-380.

Salomonson, V.V. and Appel, I. (2004), Estimating fractional snow cover from MODIS using the normalized difference snow index. Remote Sensing of Environment, 89(3), 351-360.

Serreze, M., Clark, M., Armstrong, R., McGinnis, D. \& Pulwarty, R. Characteristics of the western United States snowpack from snowpack telemetry (SNOTEL) data. Water Resour. Res. 35, 2145-2160 (1999).

S. Singh, A. Kulkarni, B. Chaudhary. Hyperspectral analysis of snow reflectance to understand the effects of contamination and grain size. Ann. Glaciol., 51 (54) (2010), pp. 83-88, 10.3189/172756410791386535.

Skiles, S. \& Painter, T. Daily evolution in dust and black carbon content, snow grain size, and snow albedo during snowmelt, Rocky Mountains, Colorado. J. Glaciol. 63, 118-132 (2017).

Stewart, I. T., Cayan, D. R., and Dettinger, M. D. (2005). Changes toward earlier streamflow timing across Western North America. J. Clim. 18, 1136-1155. doi:10.1175/JCLI3321.1

Tague, C., and Grant, G.E. (2009), Groundwater dynamics mediate low-flow response to global warming in snow-dominated alpine regions, Water Resources Research, 45, W07421, doi:10.1029/2008WR007179.

Thackeray, Chad \& Derksen, Chris \& Fletcher, Christopher \& Hall, Alex. (2019). Snow and Climate: Feedbacks, Drivers, and Indices of Change. Current Climate Change Reports. 10.1007/s40641-019-00143-w. 
Viviroli, D., H. H. Dürr, B. Messerli, M. Meybeck, and R. Weingartner (2007), Mountains of the world, water towers for humanity: Typology, mapping, and global significance, Water resources research, 43(7), W07447, doi:10.1029/2006WR005653.

Warren, S. G. (2013), Can black carbon in snow be detected by remote sensing? Journal of Geophysical Research: Atmospheres, 118, 779-786, doi:10.1029/2012JD018476.

Warren, S. G., and Wiscombe, W. J. (1980), A model for the spectral albedo of snow, II: Snow containing atmospheric aerosols, Journal of the Atmospheric Sciences, 37(12), 2734-2745.

Westerling, A.L., 2006. Warming and Earlier Spring Increase Western U.S. Forest Wildfire Activity. Science 313, 940-943. https://doi.org/10.1126/science.1128834

Westerling, A. et al. Climate change and growth scenarios for California wildfire. Clim. Change 109, 445-463 (2011).

Whitlock, C., Higuera, P.E., McWethy, D.B., Briles, C.E., 2010. Paleoecological Perspectives on Fire Ecology: Revisiting the Fire-Regime Concept TOECOLJ 3, 6-23. https://doi.org/10.2174/1874213001003020006

Winkler, R. D. Changes in snow accumulation and ablation after a fire in south-central British Columbia. Streamline Watershed Manag. Bull. 14, 1-7 (2011).

Wiscombe, W. J., and Warren, S. G. (1980). A model for the spectral albedo of snow. I: pure snow. J. Atmos. Sci. 37(12), 2712-2733. doi:10.1175/15200469(1980)037<2712:AMFTSA>2.0.CO;2

Zhonghai Jin, Thomas P. Charlock, Ping Yang, Yu Xie, Walter Miller. Snow optical properties for different particle shapes with application to snow grain size retrieval and MODIS/CERES radiance comparison over Antarctica. Remote Sensing of Environment, 112 (9) (2008), pp. 3563 3581, 10.1016/j.rse.2008.04.011 ISSN 0034-4257.

Zhuosen Wang, Angela M. Erb, Crystal B. Schaaf, Qingsong Sun, Yan Liu, Yun Yang, Yanmin Shuai, Kimberly A. Casey, Miguel O. Román, Early spring post-fire snow albedo dynamics in high latitude boreal forests using Landsat-8 OLI data, Remote Sensing of Environment, Volume 185, 2016, Pages 71-83, ISSN 00344257, https://doi.org/10.1016/j.rse.2016.02.059. 


\section{Appendices}

Appendix A - NLCD Fire Maps

2001 NLCD - Boulder Fire Perimeter

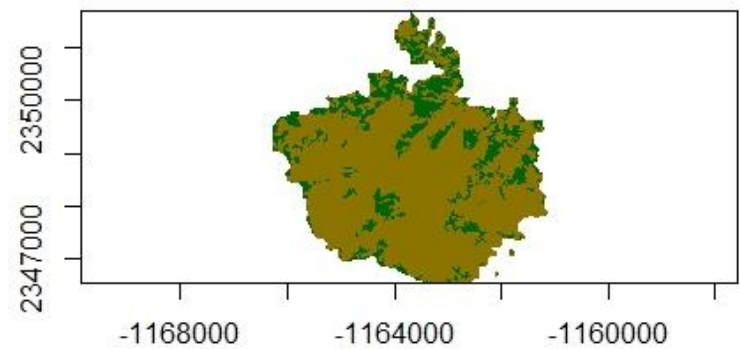

2016 NLCD - Cliff Creek Fire Perimeter

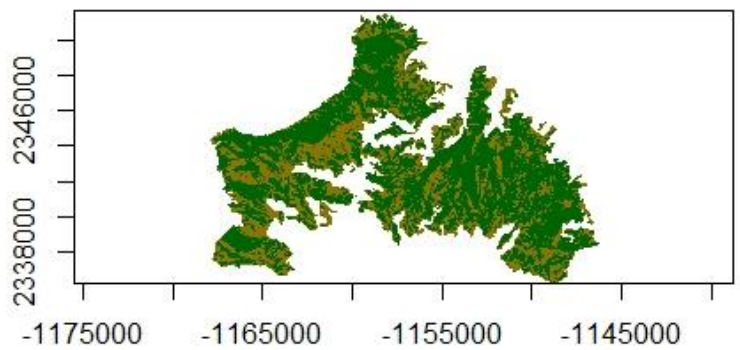

2011 NLCD - Horsethief Canyon Fire Perimeter

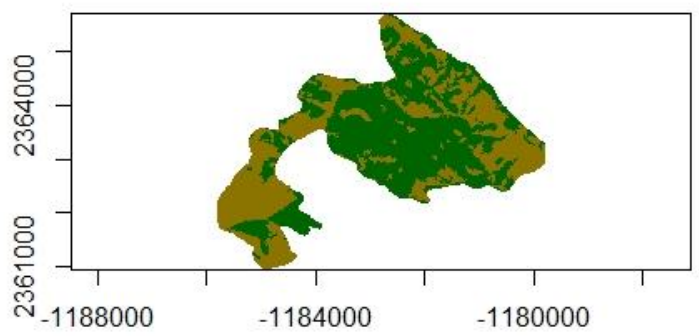

2004 NLCD - Purdy Fire Perimeter

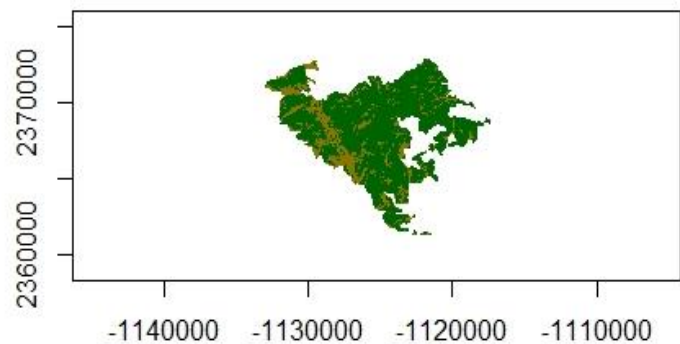

2008 NLCD - Bull Fire Perimeter

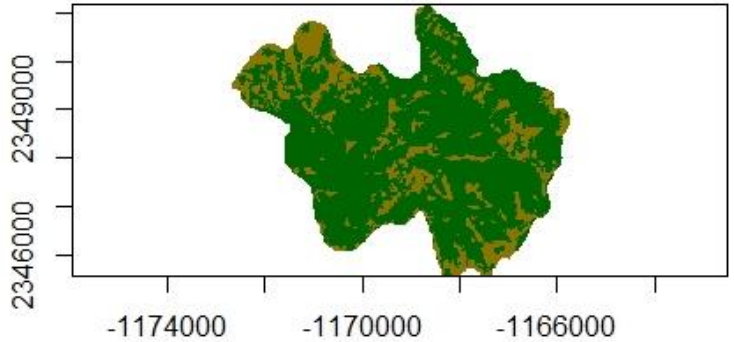

2001 NLCD - Green Knoll Fire Perimeter

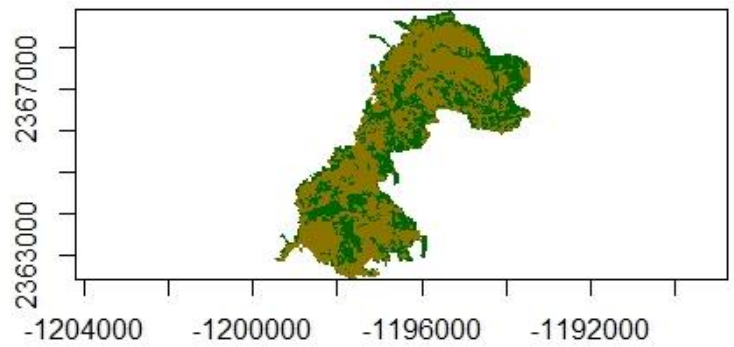

2016 NLCD - Lava Mountain Fire Perimeter

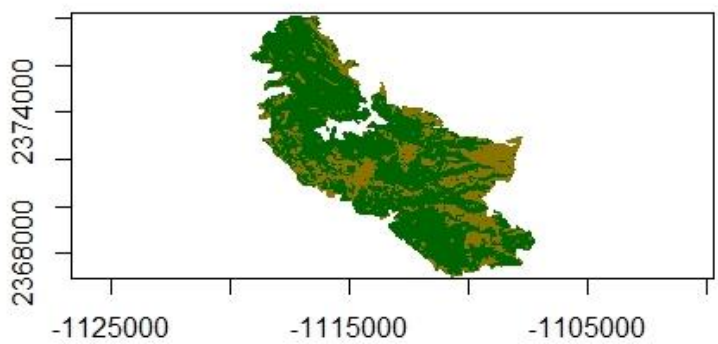

2011 NLCD - Roosevelt Fire Perimeter

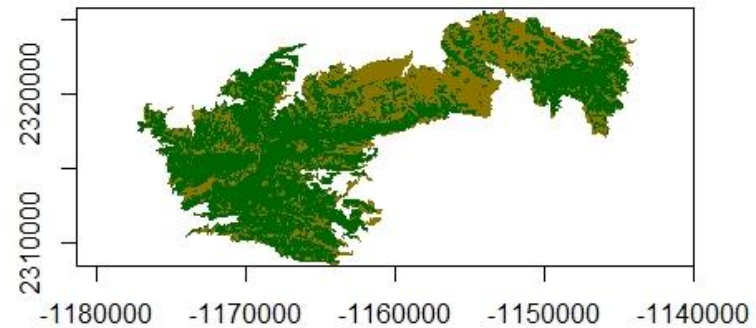

Figure 10. NLCD site maps for each individual fire. Areas within each burn perimeter were classified as either forest (green) or open (brown). 
Appendix B-Normalized Pre-fire vs. Post-fire LSA
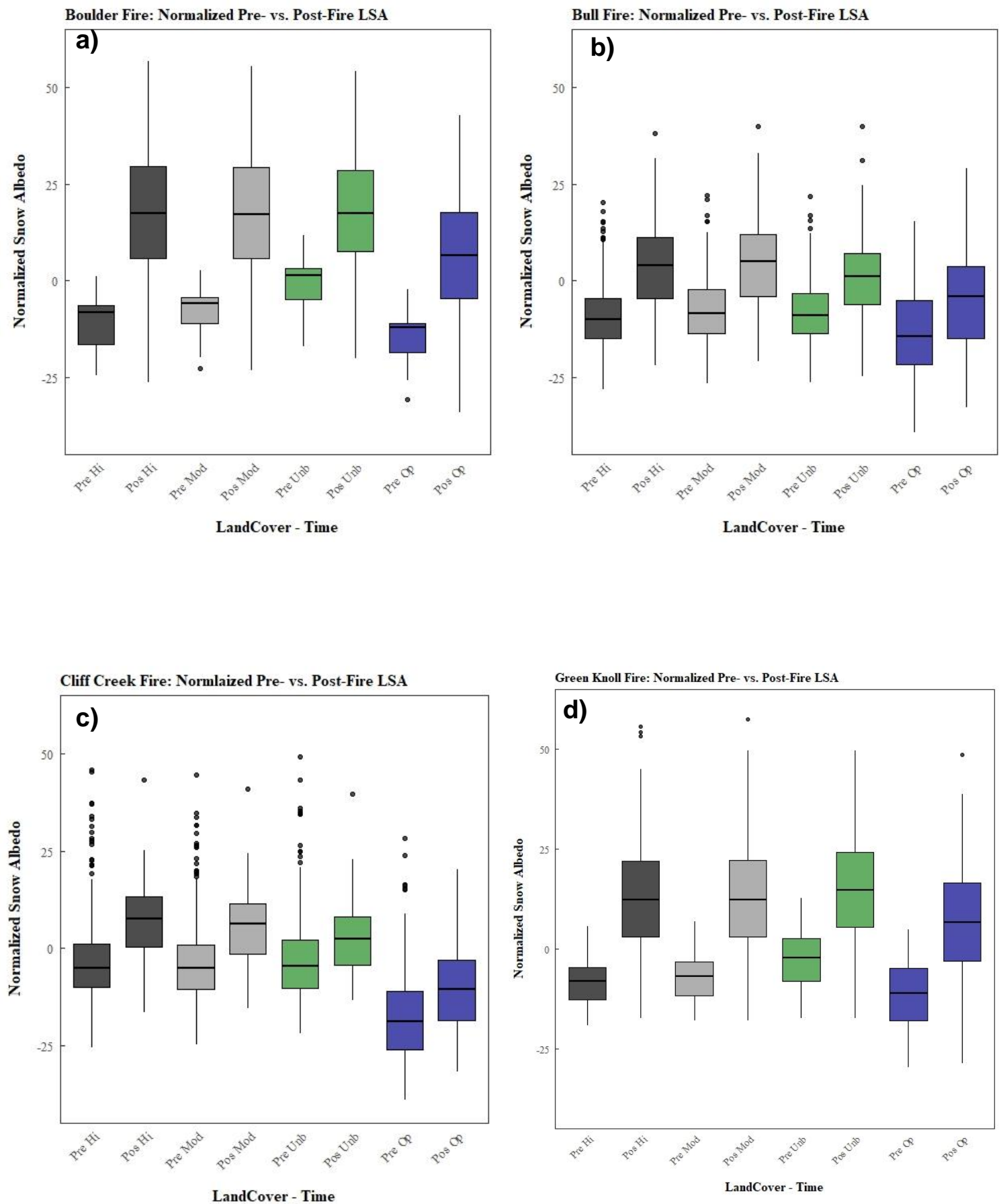

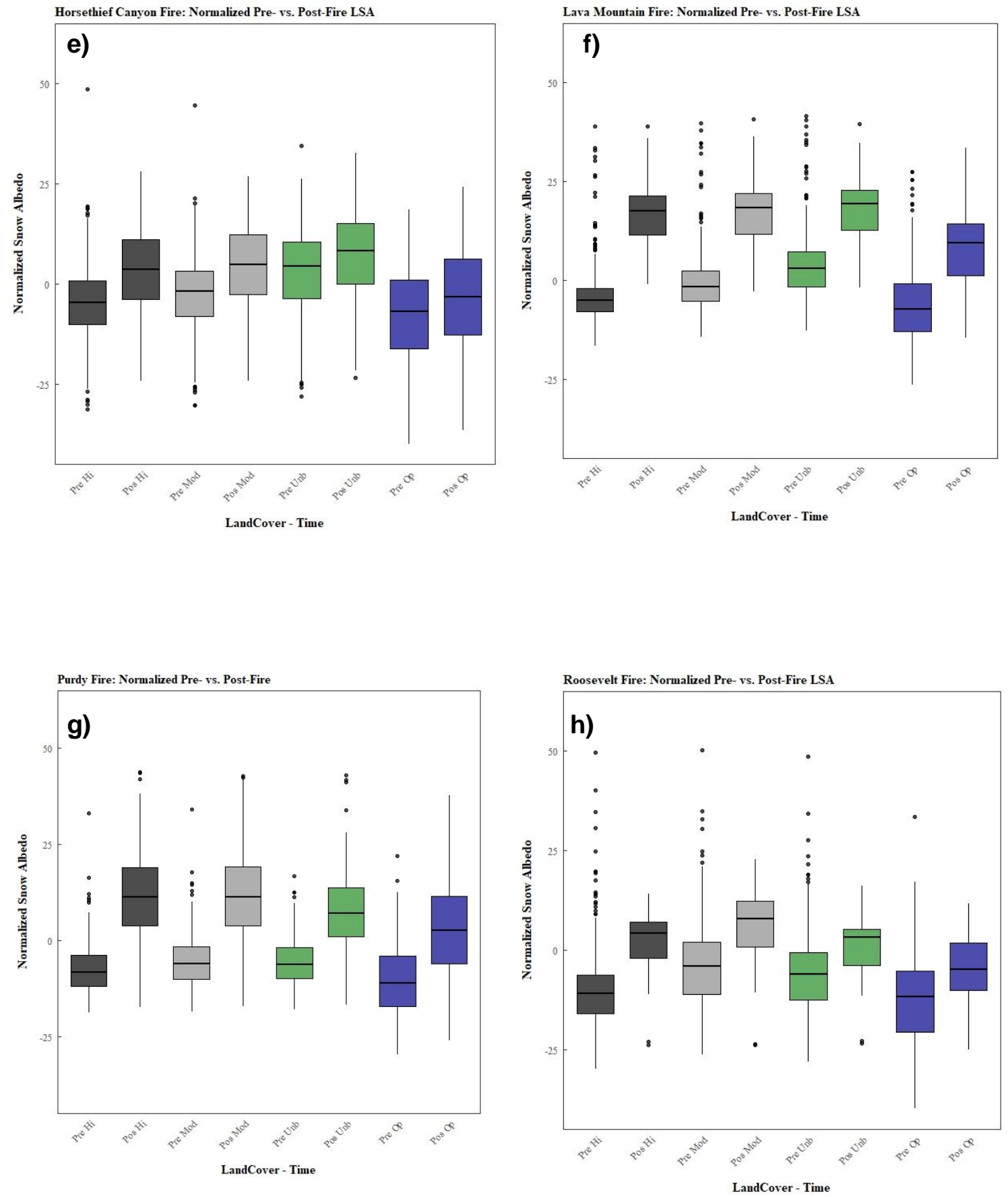

Figure 11. Pre-fire and post-fire normalized LSA for each fire, relative to burn severity. a) Boulder Fire b) Bull Fire c) Cliff Creek Fire d) Green Knoll Fire e) Horsethief Canyon Fire f) Lava Mountain Fire g) Purdy Fire h) Roosevelt Fire 
Appendix C - Post-fire Landscape Snow Albedo
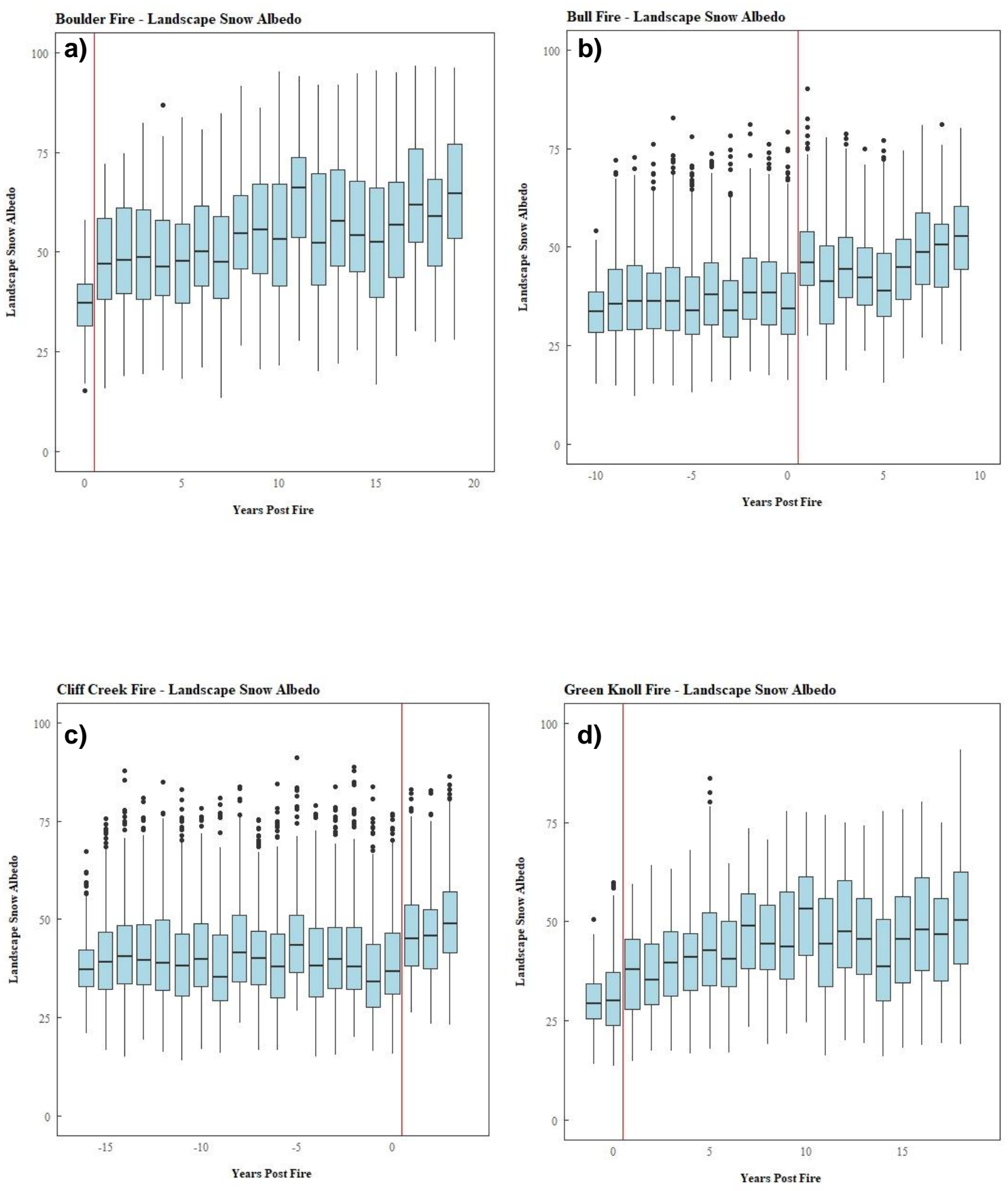

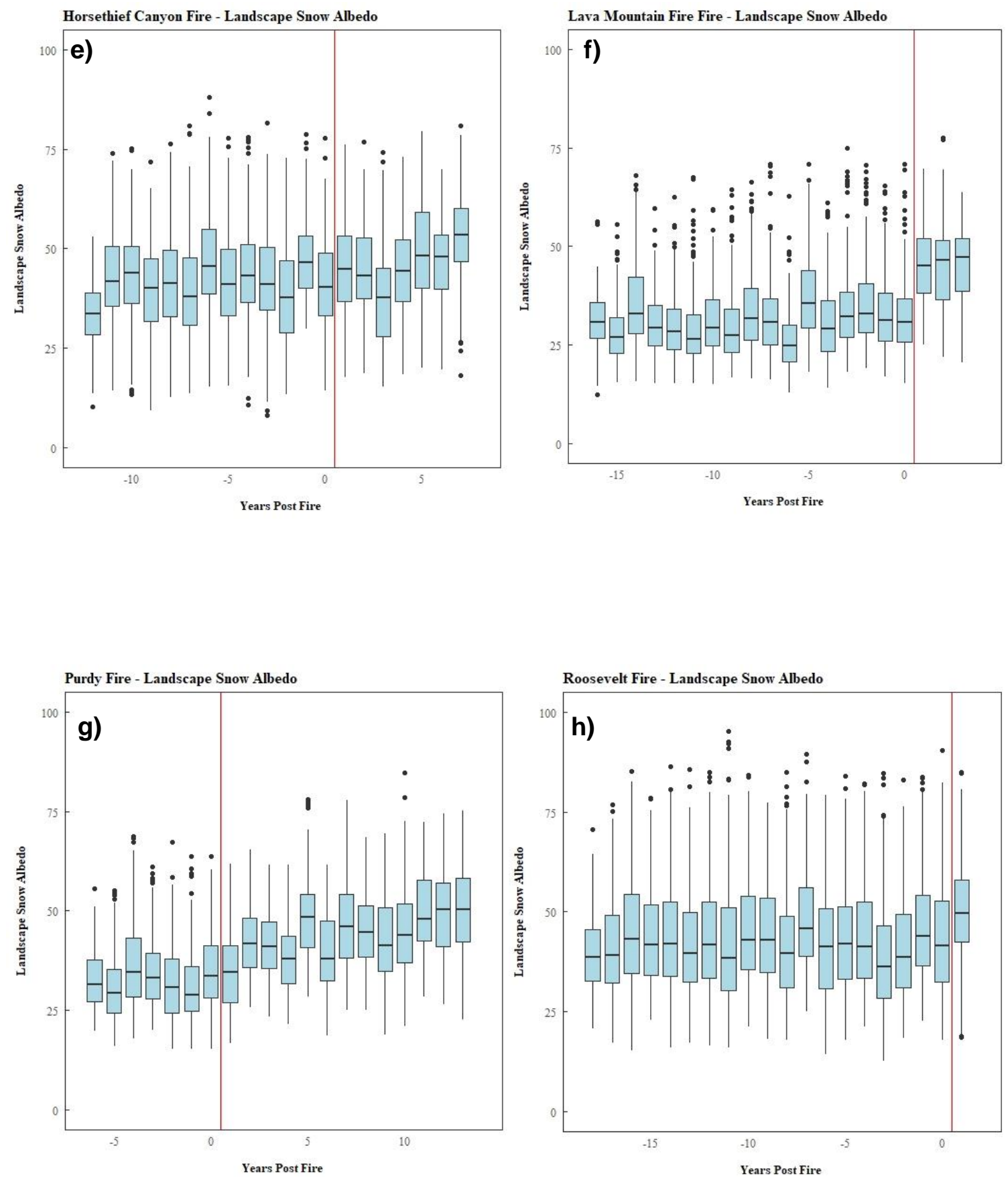

Figure 12. Post-fire landscape snow albedo separated by each fire. a) Boulder Fire b) Bull Fire c) Cliff Creek Fire d) Green Knoll Fire e) Horsethief Canyon Fire f) Lava Mountain Fire g) Purdy Fire h) Roosevelt Fire 

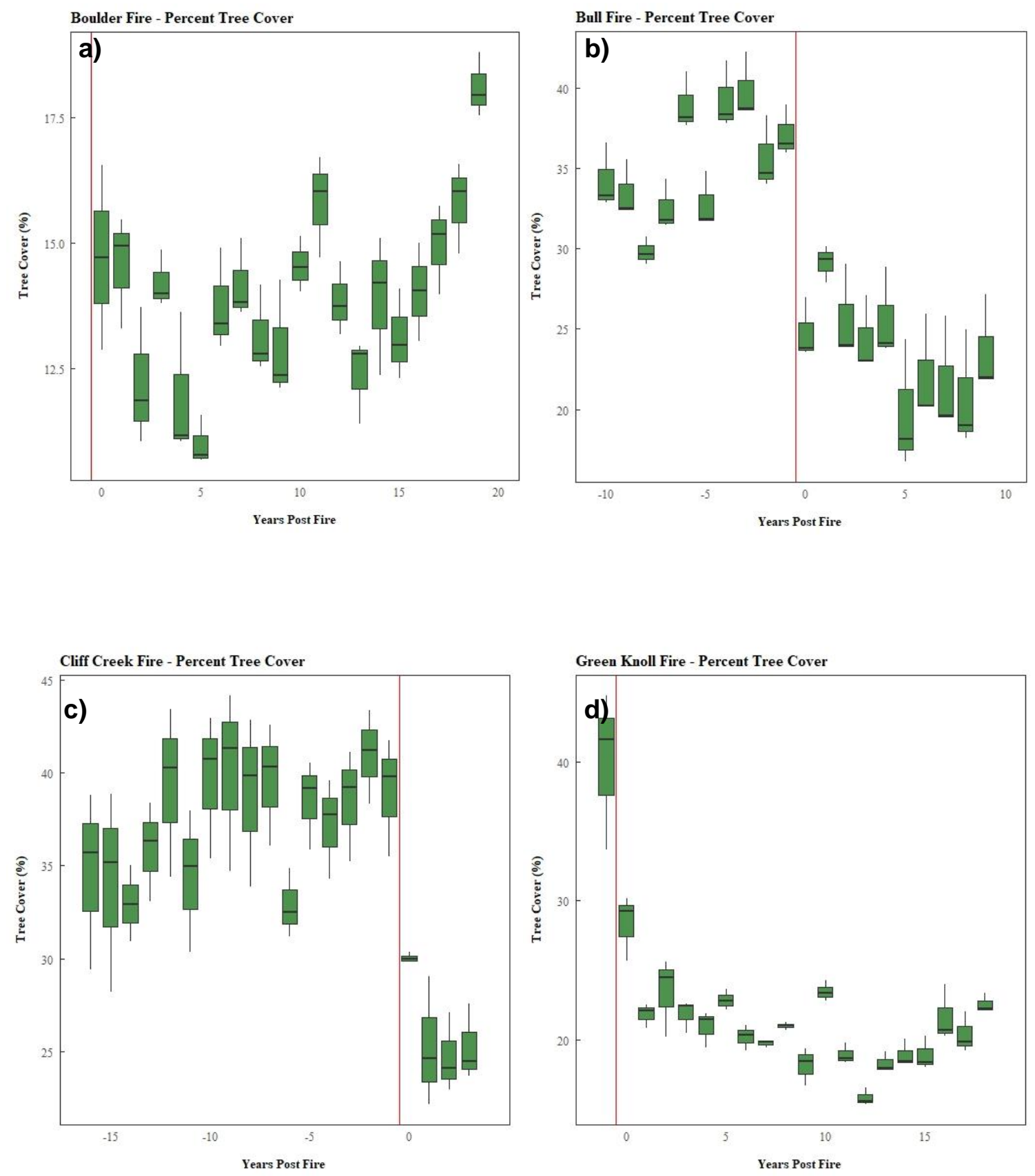

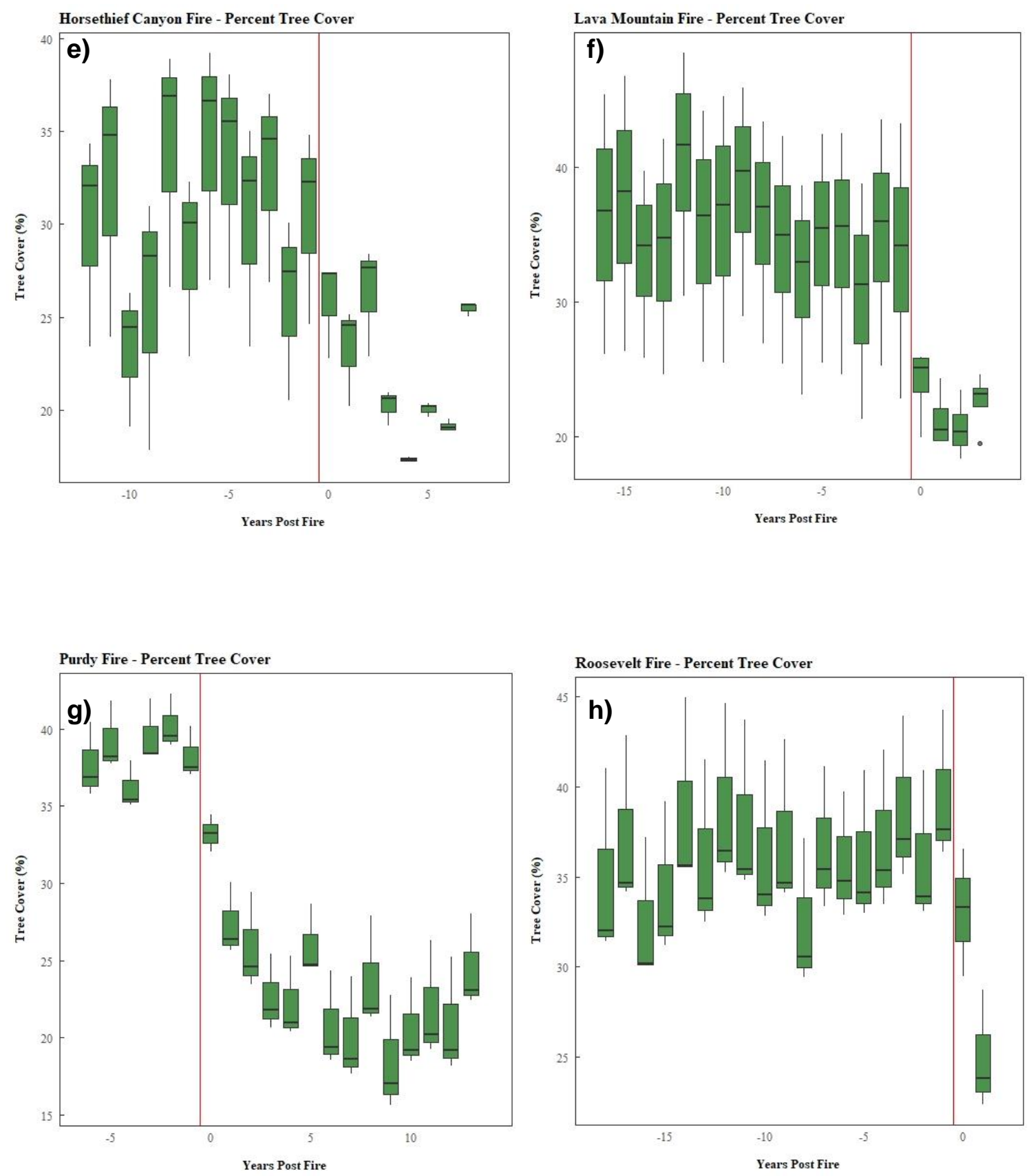

Figure 13. Post-fire forest density measurements separated by fire. a) Boulder Fire b) Bull Fire c) Cliff Creek Fire d) Green Knoll Fire e) Horsethief Canyon Fire f) Lava Mountain Fire g) Purdy Fire h) Roosevelt Fire 
a) Boulder Fire - Post-Fire Snow Albedo Change Normalized to the Buffer Area

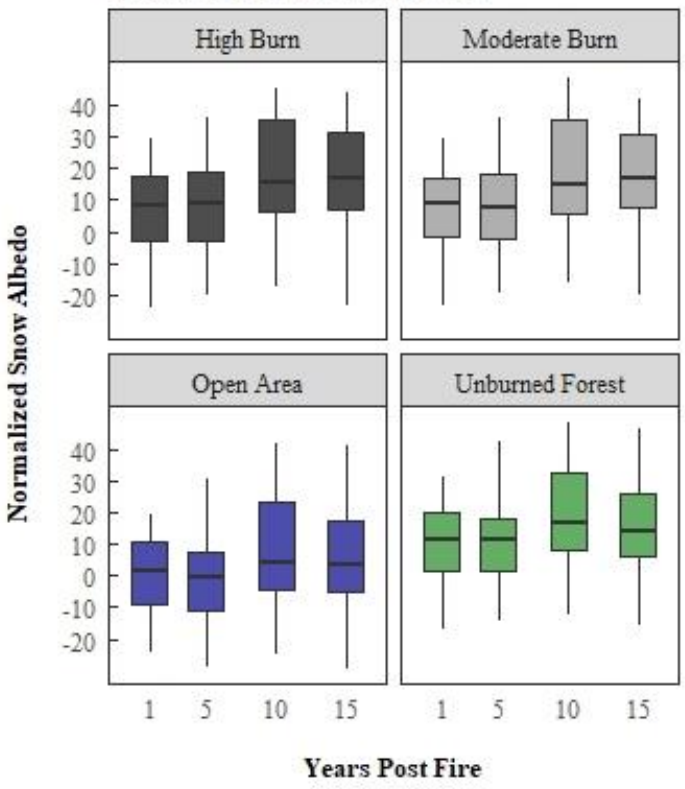

C) Cliff Creek Fire - Post-Fire Snow Albedo Change Normalized to the Buffer Area

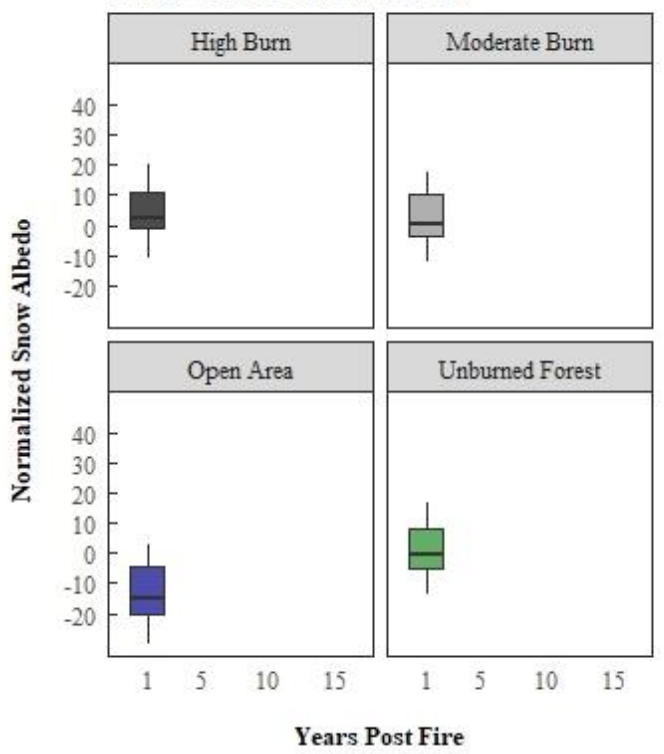

b) Bull Fire - Post-Fire Snow Albedo Change Normalized to the Buffer Area

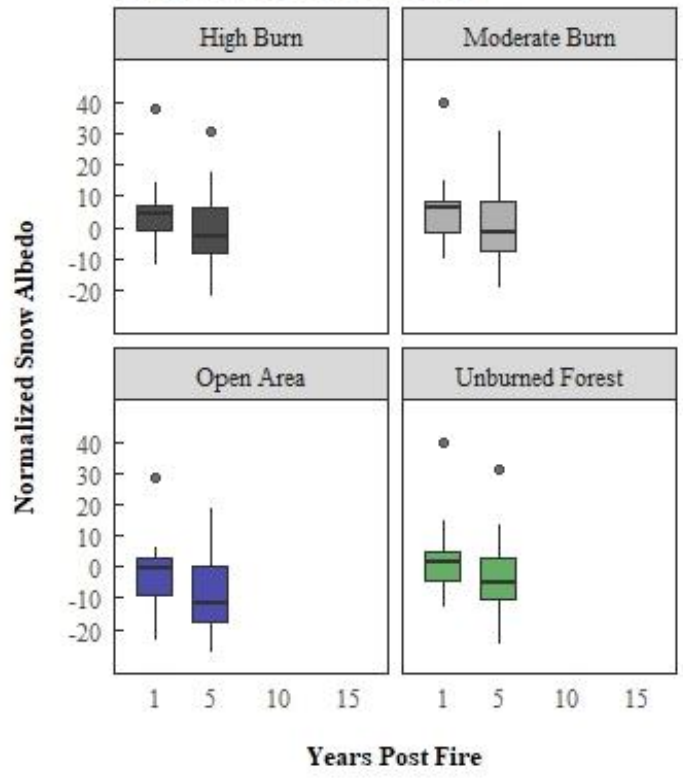

d) Green Knoll Fire - Post-Fire Snow Albedo Change

d) Normalized to the Buffer Area

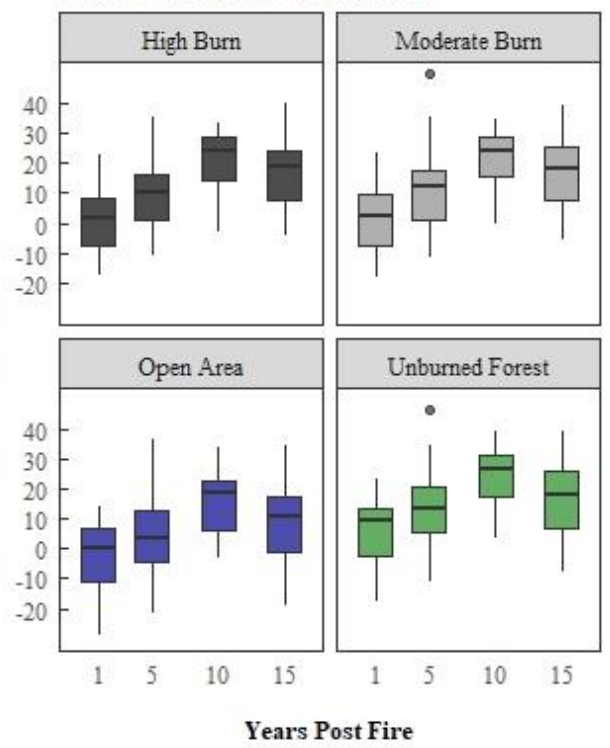


e) Horsethief Canyon Fire - Post-Fire Snow Albedo Change Normalized to the Buffer Area

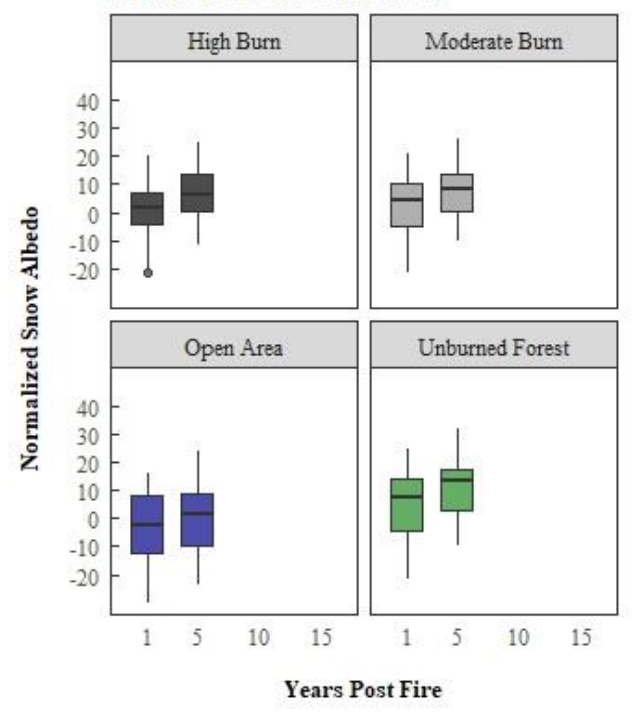

f) Lava Mountain Fire - Post-Fire Snow Albedo Change Normalized to the Buffer Area

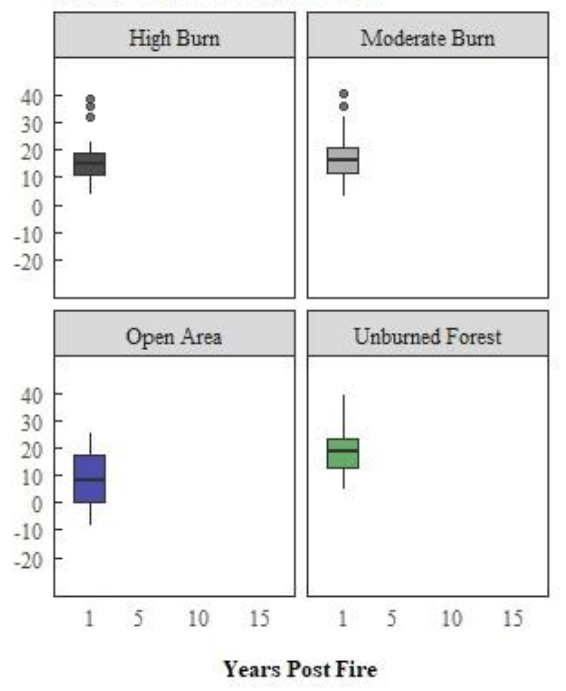

g) Purdy Fire - Post-Fire Snow Albedo Change Normalized to the Buffer Area

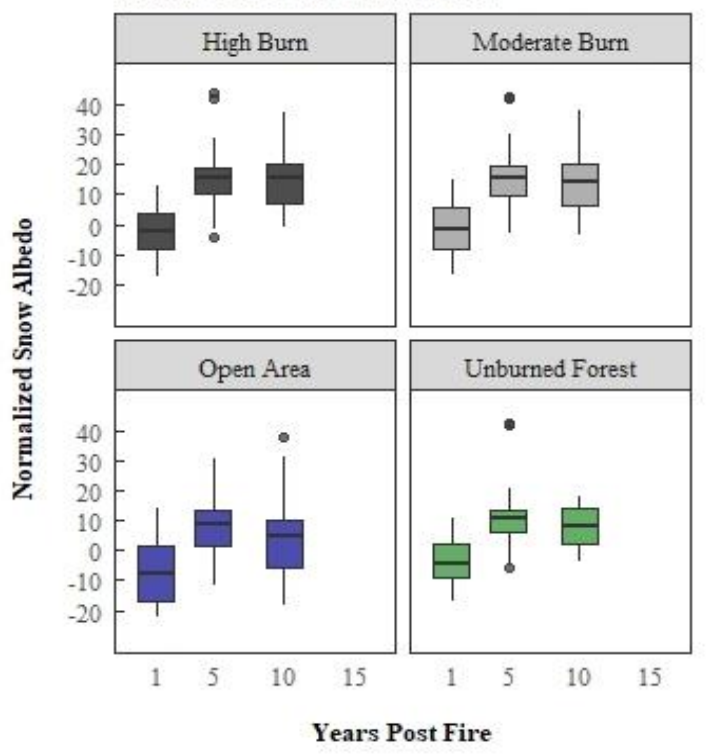

h) Roosevelt Fire - Post-Fire Snow Albedo Change Normalized to the Buffer Area

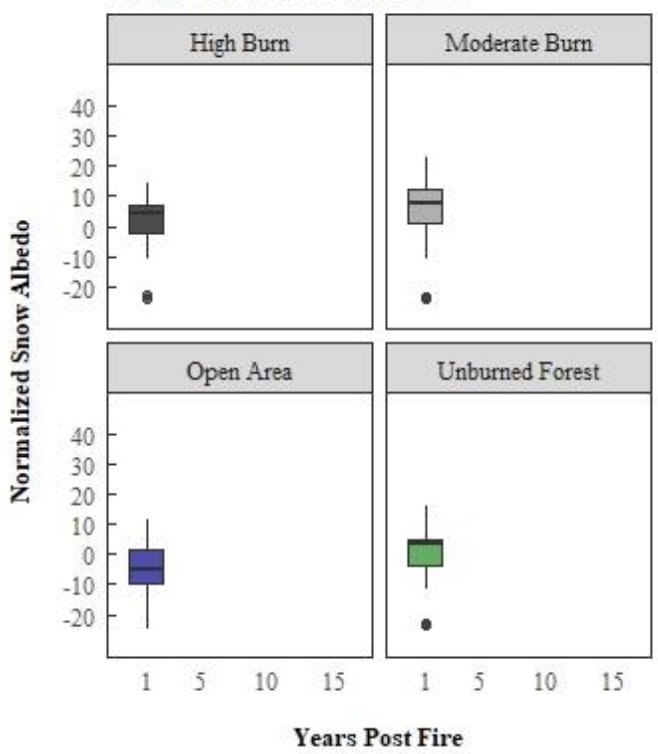

Figure 14. Post-fire normalized landscape snow albedo per 5-year subsets in order to observe the rate of PFSAC relative to each burn severity for each fire. a) Boulder Fire b) Bull Fire c) Cliff Creek Fire d) Green Knoll Fire e) Horsethief Canyon Fire f) Lava Mountain Fire g) Purdy Fire h) Roosevelt Fire 